\title{
Increasing the reactant conversion through induced oscillations in a Continuous Stirred Tank Reactor by using PI control
}

\author{
Manuel F. Pérez-Polo ${ }^{\mathrm{a}^{*}}$, Manuel Pérez-Molina ${ }^{\mathrm{b}}$ \\ Departamento de Física, Ingeniería de Sistemas y Teoría de la Señal, \\ Escuela Politécnica Superior, Universidad de Alicante. \\ Campus de San Vicente, Alicante, Spain. \\ acE-mail: manolo@dfists.ua.es. ${ }^{\mathrm{b}}$ E-mail: $\underline{\text { ma_perez_m@hotmail.com }}$
}

\begin{abstract}
We report a strategy to increase the reactant conversion in a continuous stirred tank reactor (CSTR) to produce propylene glycol through induced oscillations generated by two controllers $\mathrm{PI}_{1}$ and $\mathrm{PI}_{2}$ that manipulate the reactor outlet flow and the coolant flow rate respectively. It is shown that an adequate parameter choice for the PI controllers allows one to derive sustained oscillations in the concentrations and reactor temperature, which in turn allows increasing the propylene glycol production. For a suitable choice of the $\mathrm{PI}_{1}$ and $\mathrm{PI}_{2}$ controller parameters, we use a complete reactor model that provides with physically feasible parameters. The issues of external disturbance rejection, self-oscillations and stability have also been discussed. The analytical calculations are verified by means of full numerical simulations.
\end{abstract}

\section{Keywords}

Continuous stirred tank reactor, Induced oscillations, Production increase, PI control, Disturbance rejection, Stability.

$\mathrm{a}^{*}$ Author to whom correspondence should be addressed 


\section{Introduction}

The continuous stirred tank reactors (CSTR) in which a simple irreversible reaction $\mathrm{A} \rightarrow \mathrm{B}$ occurs has been widely used for investigating nonlinear phenomena [14]. The study of oscillating behaviors in a CSTR, with and without control, has shown that steady states, limit cycles and even chaotic behaviors can be obtained [5-7]. The control of flow rate, robust control of temperature, uncertainties and chaotic behavior in a CSTR have been reported in Refs [8-12], whereas self-oscillating and chaotic behavior with PI control appear in Refs [7] and [13].

In this paper we research a strategy to increase the reactant conversion in a CSTR for propylene glycol production. The inlet flow rate to the CSTR is formed by a mixture of propylene oxide, water with sulfur acid and methanol. The reaction in the CSTR is exothermic and can be considered as a pseudo first order reaction, whose thermodynamic data can be found in Ref. [14]. It should be noted that self-oscillating and chaotic behaviors of a CSTR for propylene glycol production without control have been studied in Ref. [12].

In prior works [1-6], [15-20], simple models considering only two independent variables of a controlled CSTR (such as concentration and temperature) have been analyzed to exploit the oscillating behavior. In this paper, a more general model is considered taking into account the mass balance of inert components (water with sulfur acid and methanol), the energy balances in the reactor and the coolant jacket and the equations of the control system. The control system is formed by a $\mathrm{PI}_{1}$ controller to manipulate the liquid flow leaving the reactor and another $\mathrm{PI}_{2}$ controller manipulates the flow rate of cooling liquid towards the reactor jacket [21]. The oscillatory behavior can be obtained through three different procedures as a function of the constants of the $\mathrm{PI}_{2}$ controller.

In the first procedure, the integral action of the $\mathrm{PI}_{2}$ controller is set to zero with the purpose of determining a curve with a cusp point and a lobe curve so that the selfoscillating behavior is reached for the points that are outside the cusp point curve and inside the lobe curve. In this case, the minimum input reactant concentration and the conversion are analyzed. Since such region for self-oscillating behavior can be very 
small, we consider a second procedure in which the proportional constant of the $\mathrm{PI}_{2}$ controller is determined by imposing the condition for self-oscillating behavior, regardless the existence of the cusp point and lobe curves. The third procedure assumes the same $\mathrm{PI}_{1}$ controller, but the $\mathrm{PI}_{2}$ controller includes an integral action to manipulate the coolant flow rate, thanks to which the mean value of the temperature coincides with the set point. In this case, the rejection of disturbances in the inlet flow rate and the stability of the limit cycles have been discussed. With the three previous procedures we demonstrate that it is possible to increase the yield of propylene-glycol from the analysis of the induced oscillations generated by the control system, which employs physically feasible values for the control signals.

\section{Equations of CSTR model}

The production of propylene glycol (C) from propylene oxide (A), water containing a small quantity of $\mathrm{H}_{2} \mathrm{SO}_{4}$ (B) and methanol (M) is considered in a CSTR with two PI controllers, whose layout is depicted in Fig 1. The operation conditions under which such reaction can occur are discussed in Refs. [12], [14], [21-22].

Figure 1

The equations of mass balance for the reactor are given by:

$$
\begin{gathered}
\frac{d V}{d t}=F_{0}-F \\
\frac{d C_{A}}{d t}=\frac{F_{0}}{V}\left(C_{A 0}-C_{A}\right)-k \cdot C_{A} ; \frac{d C_{B}}{d t}=\frac{F_{0}}{V}\left(C_{B 0}-C_{B}\right)-k \cdot C_{A} \\
\frac{d C_{C}}{d t}=\frac{F_{0}}{V}\left(-C_{C}\right)+k C_{A} ; \frac{d C_{M}}{d t}=\frac{F_{0}}{V}\left(C_{M 0}-C_{M}\right) \\
k=\alpha \cdot e^{-E / R \cdot T}
\end{gathered}
$$

where $F_{0}$ and $F$ are the inlet and outlet flow rates, $C_{A 0}, C_{B 0}, C_{C 0}$ and $C_{M 0}$ are the molar concentrations of the inlet streams, and $C_{A}, C_{B}, C_{C}$ and $C_{M}$ are the molar concentrations of the outlet streams. Taking into account that there is a water excess, the velocities of the reactions in equations (2) and (3) have been approximated by $-r_{A}=-r_{B}=r_{C} \approx k C_{A}$. 
Equation (4) expresses the Arrhenius law, in which $T$ is the reactor temperature. The inlet volumetric flow rate $F_{0}$ is determined from the molar flow rates $F_{A 0}, F_{B 0}, F_{M 0}$ of the inlet streams for $A, B$ and $M$ as:

$$
F_{0}=\frac{F_{A 0}}{\rho_{A 0}}+\frac{F_{B 0}}{\rho_{B 0}}+\frac{F_{M 0}}{\rho_{M 0}}
$$

where $\rho_{A 0}, \rho_{B 0}$ and $\rho_{M 0}$ are the molar densities of the pure components $A, B$ and $M$ respectively. The values of the inlet concentrations $C_{A 0}, C_{B 0}$ and $C_{M 0}$ are given by:

$$
C_{A 0}=\frac{F_{A 0}}{F_{0}} ; \quad C_{B 0}=\frac{F_{B 0}}{F_{0}} ; \quad C_{M 0}=\frac{F_{M 0}}{F_{0}}
$$

The energy balance for the reactor can be written as:

$$
V C_{P R} \frac{d T}{d t}=F_{A 0} c_{P S}\left(T_{0}-T\right)+\left(-\Delta H_{R}\right) \alpha C_{A} V \exp (-E / R T)-U A_{j}\left(T-T_{j}\right)
$$

where $-\Delta H_{r}$ is the reaction enthalpy, $U$ is the overall heat transfer coefficient of the jacket, $A_{j}$ is the heat transfer area, $T_{j}$ is the jacket temperature and $T_{0}$ is the inlet stream temperature. The parameter $c_{P S}$ is defined as:

$$
c_{P S}=c_{P A}+\frac{F_{B 0}}{F_{A 0}} c_{P B}+\frac{F_{M 0}}{F_{A 0}} c_{P M}
$$

where $c_{P A}, c_{P B}, c_{P M}$ are the molar heat capacities of $A, B, M$ respectively, whereas the parameter $C_{P R}$ in equation (7) is calculated as:

$$
c_{P R}=c_{P A} C_{A}+c_{P B} C_{B}+c_{P C} C_{C}+c_{P M} C_{M}
$$

where $c_{P C}$ and $C_{C}$ are the molar heat capacity and concentration of the propylene glycol respectively. The energy balance for the jacket is given by: 


$$
\frac{d T_{j}}{d t}=\frac{F_{j}}{V_{j}}\left(T_{j 0}-T_{j}\right)+\frac{U A_{j}}{\rho_{j} c_{P j} V_{j}}\left(T-T_{j}\right)
$$

where $F_{j}, \rho_{j}$ and $c_{p j}$ are respectively the volumetric flow rate, the density and the heat capacity of cooling water, $V_{j}$ is the jacket volume and $T_{j 0}, T_{j}$ are the temperature of the inlet cooling and the mean temperature of the jacket respectively. Equations (1)-(10) constitute the reactor model without control. In addition, it is assumed that two PI controllers are controlling the process by manipulating the inlet coolant flow rate $F_{j}$ and the outlet flow rate $F$. The equations of the PI controllers are the following ones:

$$
\begin{gathered}
F(t)=F_{s}+K_{v}\left[\left(V(t)-V_{s}\right)+\frac{1}{t_{1}} \int_{0}^{t}\left(V(\sigma)-V_{s}\right) d \sigma\right] \\
F_{j}(t)=F_{j s}+K_{t}\left[\left(T(t)-T_{s e t}\right)+\frac{1}{t_{2}} \int_{0}^{t}\left(T(\sigma)-T_{\text {set }}\right) d \sigma\right]
\end{gathered}
$$

where $F_{s}$ and $F_{j s}$ are the steady state values for the outlet flow rate and the inlet coolant flow rate respectively, $V_{s}$ is the steady state reactor volume, $T_{\text {set }}$ is the temperature set point, $K_{v}$ and $K_{t}$ are the controller proportional constants and $t_{1}, t_{2}$ are the integral actions. For the sake of simplifying the mathematical treatment, it is useful to introduce dimensionless variables as follows:

$$
\begin{gathered}
\tau=\frac{F_{0 s} t}{V_{s}} ; x_{1}=\frac{V}{V_{s}} ; x_{2 a}=\frac{C_{A}}{C_{A 0}^{\prime}} ; x_{2 a 0}=\frac{C_{A 0}}{C_{A 0}^{\prime}} ; x_{2 b}=\frac{C_{B}}{C_{B 0}^{\prime}} ; x_{2 b 0}=\frac{C_{B 0}}{C_{B 0}^{\prime}} \\
x_{2 c}=\frac{C_{C}}{C_{C 0}^{\prime}} ; x_{2 m}=\frac{C_{M}}{C_{M 0}^{\prime}} ; x_{2 m 0}=\frac{C_{M 0}}{C_{M 0}^{\prime}} \\
\frac{1}{x_{3}}=\frac{E}{R T} ; \frac{1}{x_{30}}=\frac{E}{R T_{0}} ; \frac{1}{x_{4}}=\frac{E}{R T_{j}} ; \frac{1}{x_{40}}=\frac{E}{R T_{j 0}} ; \frac{1}{x_{s e t}}=\frac{E}{R T_{s e t}} \\
x_{5}=\frac{F}{F_{0 s}} ; x_{50}=\frac{F_{0}}{F_{0 s}} ; x_{6}=\frac{F_{j}}{F_{j s}}
\end{gathered}
$$

where $F_{0 s}$ is the steady state value for the inlet flow rate and $C^{\prime}{ }_{A 0}, C^{\prime}{ }_{B 0}, C^{\prime}{ }_{C 0}, C^{\prime}{ }_{M 0}$ are reference concentrations in steady state obtained after a transient reactor start process. The dimensionless constants of the PI controllers are given by: 


$$
K_{v d}=K_{v} \frac{V_{s}}{F_{0 s}} ; t_{1 d}=t_{1} \frac{F_{0 s}}{V_{s}} ; K_{t d}=K_{t} \frac{T_{0}}{F_{j s}} ; t_{2 d}=t_{2} \frac{F_{0 s}}{V_{s}}
$$

By introducing the parameters:

$$
\begin{gathered}
c_{0}=\frac{V_{s} \alpha}{F_{0 s}} ; c_{01}=\frac{V_{s} \alpha}{F_{0 s}} \frac{C_{A 0}^{\prime}}{C_{B 0}^{\prime}} ; c_{02}=\frac{V_{s} \alpha}{F_{0 s}} \frac{C_{A 0}^{\prime}}{C_{C 0}^{\prime}}: c_{1}=\frac{V_{s} R\left(-\Delta H_{R}\right) C_{A 0}^{\prime}}{F_{0 s} E C_{p s}} \alpha \\
c_{2}=\frac{U A}{F_{A 0} c_{p s}} ; c_{3}=\frac{V_{s} F_{j s}}{V_{j} F_{0 s}} ; c_{4}=\frac{U A V_{s}}{\rho_{j} c_{p j} V_{j} F_{0 s}}
\end{gathered}
$$

the equations for the CSTR can be expressed as:

$$
\left.\begin{array}{l}
\frac{d x_{1}}{d \tau}=x_{50}-x_{5} \\
\frac{d x_{2 a}}{d \tau}=\frac{x_{50}}{x_{1}}\left(x_{2 a 0}-x_{2 a}\right)-c_{0} x_{2 a} \exp \left(-1 / x_{3}\right) \\
\frac{d x_{2 b}}{d \tau}=\frac{x_{50}}{x_{1}}\left(x_{2 b 0}-x_{2 b}\right)-c_{01} x_{2 a} \exp \left(-1 / x_{3}\right) \\
\frac{d x_{2 c}}{d \tau}=-\frac{x_{50}}{x_{1}} x_{2 c}+c_{02} x_{2 a} \exp \left(-1 / x_{3}\right) \\
\frac{d x_{2 m}}{d \tau}=\frac{x_{50}}{x_{1}}\left(x_{2 m o}-x_{2 m}\right) \\
c_{y} \frac{d x_{3}}{d \tau}=\frac{1}{x_{1}}\left(x_{30}-x_{3}\right)+c_{1} x_{2 a} \exp \left(-1 / x_{3}\right)-\frac{c_{2}}{x_{1}}\left(x_{3}-x_{4}\right) \\
\frac{d x_{4}}{d \tau}=c_{3} x_{6}\left(x_{40}-x_{4}\right)+c_{4}\left(x_{3}-x_{4}\right) \\
\frac{d x_{5}}{d \tau}=K_{v d}\left(x_{50}-x_{5}\right)+\frac{K_{v d}}{t_{1 d}}\left(x_{1}-1\right) \\
\frac{d x_{6}}{d \tau}=\frac{K_{t d}}{x_{30}}\left(\frac{d x_{3}}{d \tau}+\frac{1}{t_{2 d}}\left(x_{3}-x_{s e t}\right)\right)
\end{array}\right\}
$$

where the parameter $c_{y}$ depends on the absolute variables $C_{A}, C_{B}, C_{C}$, and $C_{M}$ (or dimensionless variables $x_{2 a}, x_{2 b}, x_{2 c}, x_{2 m}$ ) and it is given by:

$$
c_{y}=\frac{F_{0}}{F_{A 0} C_{P S}} \cdot\left(c_{P A} C_{A 0}^{\prime} X_{2 a}+C_{P B} C_{B 0}^{\prime} X_{2 b}+C_{P C} C_{C 0}^{\prime} X_{2 c}+C_{P M} C_{M 0}^{\prime} X_{2 m}\right)
$$


Table 1 show the reactor parameter values and the nominal operating conditions, which will be justified later on the basis of the values obtained in the simulation process. A nomenclature of the dimensionless variables is provided in table 2.

Table 1

Table2

It is interesting to remark that the steady-state behavior of the rector can be obtained equating the derivatives of Eqs (16) to zero, which allows eliminating $\mathrm{x}_{2 \mathrm{a}}$ and $\mathrm{x}_{4}$ between the second, sixth and seventh equations. Then one obtains an equilibrium equation which represents the steady-state heat balance. In such equation we can identify a curve of generated heat (a sigmoid) and a straight line which represents the removed heat [7], [13], [14]. In the most general case, these curves intersect at three points of low, middle and high temperature.

Without control, only points of low or high temperature could be reached, which would respectively imply a very low conversion and loses of reactant due to volatility of propylene oxide. This undesirable behavior can be modified by adding the $\mathrm{PI}_{2}$ controller, which changes the slope of the straight line of removed heat so that there is only one stable intersection point between the generated heat curve and the straight line of removed heat.

\section{Induced oscillations originated by the controllers $P I_{1}$ and $P I_{2}$ with $t_{2 d}=\infty$}

In this section, the conditions to obtain induced oscillations through the $\mathrm{PI}_{1}$ and $\mathrm{PI}_{2}$ controllers are researched (simplified models in which the self-oscillations are used to improve the performance of different kind of reactors can be found in Refs [23-26]). It will be assumed that the integral action of the $\mathrm{PI}_{2}$ controller, which manipulates the coolant flow rate, takes the maximum possible value $t_{2 d}=\infty$. According to Eq (12) and the last equation of (16), the coolant flow rate can be written as follows:

$$
F_{j}=F_{j s}+K_{t}\left(T-T_{s e t}\right) \Rightarrow x_{6}=1+K_{d}\left(x_{3}-x_{\text {set }}\right) ; K_{d}=K_{t d} / x_{30}
$$


On the other hand, taking derivate with respect to $\tau$ in the eighth equation of (16) and substituting the first equation of (16) in the resulting equation, we obtain a second-order linear differential equation on $x_{5}$, for which assuming the condition

$$
K_{v d} / t_{1 d}>\left(K_{v d} / 2\right)^{2}
$$

we obtain that the roots of the characteristic equation are conjugate complex with negative real part. Consequently, in steady state it is verified that $x_{1}(\tau) \rightarrow 1$, which according to the first equation of (16) implies that $x_{5}(\tau) \rightarrow x_{50}$. Substituting Eq (18) into the seventh equation of (16), the analysis of the induced oscillations is carried out considering the steady state for the reactor. From the second equation of (16) and the previous considerations it is deduced that:

$$
\begin{gathered}
x_{2 a}^{*}=\frac{x_{50} x_{2 a 0}}{x_{50}+c_{0} \exp \left(-1 / x_{3}^{*}\right)} \\
x_{30}-x_{3}^{*}+c_{1} x_{2 a}^{*} \exp \left(-1 / x_{3}^{*}\right)-\frac{c_{2} c_{3}\left[1+K_{d}\left(x_{3}^{*}-x_{\text {set }}\right)\right]\left(x_{3}^{*}-x_{40}\right)}{c_{3}\left[1+K_{d}\left(x_{3}^{*}-x_{\text {set }}\right)\right]+c_{4}}=0
\end{gathered}
$$

where the asterisk means equilibrium state. Equation (20) provides with $x_{2 a}^{*}$ as a function of $x_{3}^{*}$, which can be substituted into Eq (21) to obtain the relation between the inlet flow rate dimensionless temperature $x_{30}$ and the reactor equilibrium temperature $x_{3}^{*}$, i.e.:

$$
x_{30}=x_{3}^{*}-\frac{c_{1} x_{50} x_{2 a 0}}{x_{50} \exp \left(1 / x_{3}^{*}\right)+c_{0}}+\frac{c_{2} c_{3}\left[1+K_{d}\left(x_{3}^{*}-x_{\text {set }}\right)\right]\left(x_{3}^{*}-x_{40}\right)}{c_{3}\left[1+K_{d}\left(x_{3}^{*}-x_{\text {set }}\right)\right]+c_{4}}
$$

On the other hand, Eqs (16) clearly show that variables $x_{2 b}, x_{2 c}$, and $x_{2 m}$ have no effect on the equilibrium point. Consequently, the induced oscillations in the first control strategy only depend on the proportional constant $K_{d}$ of the controller $\mathrm{PI}_{2}$.

3.1 Induced oscillations originated by $\mathrm{PI}_{2}$ with $t_{2 d}=\infty$. Cusp and lobe curves 
It is clear that Eq (22) is transcendent and therefore the value of $x_{3}^{*}$ cannot be obtained as an elementary function of the rest of known parameters. However, assuming a fixed value for $x_{50}$ and $K_{d}$, the dimensionless input temperature $x_{30}$ may be plotted as a function of the dimensionless equilibrium reactor temperature $x_{3}^{*}$ taking the dimensionless input concentration $x_{2 a 0}$ of reactant $A$ as a parameter, as shown in Fig 2. It should be noted that up to four equilibrium points can appear depending on the values for $x_{30}$ and $x_{2 a 0}$. For example, taking $x_{30}=0.033$ and $x_{2 a 0}=23.5$, the reactor has two equilibrium points $\mathrm{M}$ and $\mathrm{N}$, as it can be observed in Fig 2. When the line $x_{30}=$ constant is tangent to the curve $x_{30}=f\left(x_{3}^{*}, x_{2 a 0}, K_{d}\right)$, a bifurcation phenomenon appears giving rise to an interesting dynamical behavior for the reactor [11-12], [21-22].

\section{Figure 2}

The bifurcation curve can be determined by imposing the condition $d x_{30} / d x_{3}^{*}=0$ (i.e. the condition for a local extreme) in Eq (22). Introducing the notation

$$
f\left(x_{3}^{*}\right)=\frac{c_{2} c_{3}\left[1+K_{d}\left(x_{3}^{*}-x_{\text {set }}\right)\right]\left(x_{3}^{*}-x_{40}\right)}{c_{3}\left[1+K_{d}\left(x_{3}^{*}-x_{\text {set }}\right)\right]+c_{4}}
$$

Eqs (22) and (23) allow to deduce that:

$$
\frac{d x_{30}}{d x_{3}^{*}}=1-\frac{\left(1 /\left(x_{3}^{*}\right)^{2}\right) \exp \left(1 / x_{3}^{*}\right) c_{1} x_{50}^{2} x_{2 a 0}}{\left(x_{50} \exp \left(1 / x_{3}^{*}\right)+c_{0}\right)^{2}}+\frac{\partial f\left(x_{3}^{*}\right)}{\partial x_{3}^{*}}=0
$$

From Eq (24) it follows that the input dimensionless concentration $x_{2 a 0}$ of reactant A is given by:

$$
x_{2 a 0}=\frac{1}{c_{1} x_{50}^{2}}\left(x_{3}^{*}\right)^{2} \exp \left(-1 / x_{3}^{*}\right)\left(x_{50} \exp \left(-1 / x_{3}^{*}\right)+c_{0}\right)^{2}\left(1+\frac{\partial f\left(x_{3}^{*}\right)}{\partial x_{3}^{*}}\right)
$$

Substituting Eq (25) into Eq (22), the input dimensionless temperature $x_{30}$ can be expressed as a function of the equilibrium dimensionless temperature $x_{3}^{*}$ as: 


$$
x_{30}=x_{3}^{*}-\frac{\left(x_{3}^{*}\right)^{2}}{x_{50}}\left(x_{50}+c_{0} \exp \left(-1 / x_{3}^{*}\right)\right)\left(1+\frac{\partial f\left(x_{3}^{*}\right)}{\partial x_{3}^{*}}\right)+f\left(x_{3}^{*}\right)
$$

Eqs (25) and (26) constitute the parametric equations of the bifurcation curve taking the dimensionless equilibrium reactor temperature $x_{3}^{*}$ as the parameter. Such curve has a cusp point and is the boundary that splits the plane $x_{2 a 0}-x_{30}$ into domains whose number of equilibrium points ranges from one to four [13]. The coordinates of the cusp point are determined from Eqs (25) and (26) by applying the conditions for a singular point in a plane curve, i.e.: $d x_{2 a 0} / d x_{3}^{*}=0 ; d x_{30} / d x_{3}^{*}=0$.

Another interesting dynamical behavior can be deduced from the eigenvalues of the Jacobian matrix of Eqs (16) in a generic equilibrium point. The calculation can be simplified taking into account that $t_{2 d}=\infty$ and assuming that Eq (18) and the inequality given by Eq (19) are verified. In this case, the first, eighth and ninth equations of (16) are not considered in the calculation of the Jacobian matrix in the equilibrium point. It can be shown that the equations corresponding to $x_{2 b}, x_{2 c}$ and $x_{2 m}$ provide the factor $(\lambda+$ $1)^{3}$ in the characteristic polynomial, The other three eigenvalues can be obtained from the block of the Jacobian matrix given by:

$$
J^{\prime}=\left[\begin{array}{ccc}
-x_{50}-c_{0} \exp \left(-\frac{1}{x_{3}^{*}}\right) & -c_{o} \frac{x_{2 a}^{*}}{\left(x_{3}^{*}\right)^{2}} \exp \left(-\frac{1}{x_{3}^{*}}\right) & 0 \\
\frac{c_{1}}{c_{y}^{*}} \exp \left(-\frac{1}{x_{3}^{*}}\right) & \frac{1}{c_{y}^{*}}\left[-\left(1+c_{2}\right)+c_{1} \frac{x_{2 a}^{*}}{\left(x_{3}^{*}\right)^{2}} \exp \left(-\frac{1}{x_{3}^{*}}\right)\right] & \frac{c_{2}}{c_{y}^{*}} \\
0 & c_{3} K_{d}\left(x_{40}-x_{4}^{*}\right)+c_{4} & -c_{3}\left[1+K_{d}\left(x_{3}^{*}-x_{\text {set }}\right)\right]-c_{4}
\end{array}\right]
$$

The eigenvalues associated to the matrix $J$ ' of equation of (27) can be deduced from the equation:

$$
\left|\lambda I-J^{\prime}\right|=\lambda^{3}+S_{1} \lambda^{2}+S_{2} \lambda+S_{3}=0: S_{i}=(-1)^{i} \sum\left|A_{i k}^{i k}\right|
$$

where $A^{i k}{ }_{i k}$ are the minors of the determinant of $J$ ' (Eq (27)). In accordance with the Routh-Hurwitz criterion, imposing the conditions 


$$
S_{1}>0 ; S_{2}>0 ; S_{3}>0 ; S_{1} S_{2}-S_{3}=0
$$

we obtain a set of equilibrium points $\left(x_{2 a}^{*}, x_{3}^{*}\right)$ each of them having a pair of pure imaginary eigenvalues. Substituting the equilibrium points $\left(x_{2 a}^{*}, x_{3}^{*}\right)$ into Eqs (20) and (22) we obtain the parametric equations $x_{2 a 0}=f_{1}\left(x_{3}^{*}\right) ; x_{30}=f_{2}\left(x_{3}^{*}\right)$ of the lobe curve. The analytical expressions for the previous parametric equations are much more complicated than the ones for the cusp point curve given by Eqs (25) and (26), and thus they will be computed through a modification of the algorithm described in Ref. [12]. At the boundary of the lobe, the self-oscillation frequency is determined from the roots of the equation $S_{1} \lambda^{2}+S_{3}=0$. On the other hand, values for $\left(x_{30}, x_{2 a 0}\right)$ inside the lobe curve and outside the cusp curve only provide one equilibrium point which is unstable (since it has at least one eigenvalue with positive real part). The results of the previous calculations are shown in Fig 3 a) (the sub-indices C and L refer to the cusp and lobe curves respectively).

Figure 3

On the other hand, the exact reactor oscillation frequency can only be determined at the points of the lobe curve that are outside the cusp curve. In the example considered in Fig 3 a) we assume that $x_{30}=0.032$ and $K_{d 2 L}=201.0826$, for which we obtain points $P_{1}$ and $P_{2}$ whose respective coordinates are $\left(x_{30}, x_{2 a 01}\right)=(0.032$, $23.5)$ and $\left(x_{30}, x_{2 a 02}\right)=(0.032,31.5)$. For any point $\left(x_{30}, x_{2 a 0}\right)$ lying in the segment $\mathrm{P}_{1} \mathrm{P}_{2}$ shown in Fig 3 a), the reactor will reach a self-oscillating behavior whose dimensionless frequency will be between $\omega_{1}=0.95$ and $\omega_{2}=4$, as it can be observed in Fig $3 \mathrm{~b}$ ).

The (self-oscillating) time evolution of the system variables for point $\mathrm{P}_{1}$ is shown in Fig 4. In Fig 4 a), the dimensionless concentrations of propylene oxide and propylene glycol are plotted, whereas Fig 4 b) shows the dimensionless temperatures of the reactor and the jacket, and Fig 4 c) shows the limit cycle in the $x_{2 a}(\tau)-x_{3}(\tau)$ plane. The conversion $X_{A}(t)$ of reactant $A$ (propylene oxide) and its dc mean value $X_{\text {Aos }}$ are defined as:

$$
X_{A}(t)=1-\left(C_{A}(t) / C_{A 0}\right) ; X_{\text {Aos }}=\frac{1}{t_{2}-t_{1}} \int_{t_{1}}^{t_{2}} X_{A}(t) d t
$$


where $t_{2}>t_{1}$ is the required time to reach a stable oscillation. The dc mean value $\bar{X}_{A}$ must be as large as possible for performance purposes, and it is shown in Fig 4 d).

\section{Figure 4}

3.2 Induced oscillations originated by $\mathrm{PI}_{2}$ with $t_{2 d}=\infty$. Analysis of the eigenvalues

In the previously considered case, the oscillatory behavior is subjected to the existence of the cusp and lobe curves. Nevertheless, according to the equilibrium Eqs (20) and (21) it may be possible to choose a value for the proportional constant $K_{d}$ of the controller to obtain one unstable equilibrium point. In this case, the reactor must reach an oscillating behavior around the equilibrium point. The main difficulty arises from the fact that Eqs (20) and (21) are not linear, so it is not possible to obtain an elementary analytical solution. However, it is possible to find a computational solution throughout the following steps:

- Choice of the values for $x_{2 a 0}, x_{30}, x_{50}$ and $x_{\text {set }}$.

- Choice of an admissible set of values for the dimensionless equilibrium temperatures $x^{*}$.

- For each value of $x^{*}$, the value of $f_{1}$ is given by:

$$
f_{1}=x_{30}-x_{3}^{*}+\frac{c_{1} x_{50} x_{2 a 0}}{c_{0}+x_{50} \exp \left(1 / x_{3}^{*}\right)}
$$

- For the value of $f_{1}$ given in Eq (31), only the positive values of $K_{d}$ are determined through the equation given by:

$$
f_{1}=\frac{c_{2}\left[1+K_{d}\left(x_{3}^{*}-x_{\text {set }}\right)\right]\left(x_{3}^{*}-x_{40}\right)}{\left[1+K_{d}\left(x_{3}^{*}-x_{\text {set }}\right)\right]+c_{4} / c_{3}}
$$

The appropriate set of values for $K_{d}$ are shown in Fig 5 a). Once the values of $K_{d}$ are obtained, the real part of the equilibrium point eigenvalues are plotted in Fig $5 \mathrm{~b}$ ). It 
should be noted that there is a range of values for $K_{d}$ for which the only equilibrium point is unstable, and thus an oscillating behavior may be reached by the reactor as shown in Figs 5 c) and d).

\section{Figure 5}

3.3 Induced oscillations with $\mathrm{PI}_{2}$ control.

In this subsection we consider a similar case to the one considered in subsection 3.1, but assuming that the reset time of the integral action has a finite value and that the values of $x_{2 a 0}$ and $x_{30}$ are outside of the lobe. The investigation of the self-oscillating behavior is carried out from Eqs (16) by calculating the eigenvalues of the Jacobian matrix of the linearized system at the equilibrium point. The idea is to vary the parameters $K_{d}$ and $t_{2 d}$ of the $\mathrm{PI}_{2}$ controller giving rise to pure imaginary eigenvalues. The Jacobian matrix of the linearized system at the dimensionless temperature set point $x_{3}^{*}$ is given by:

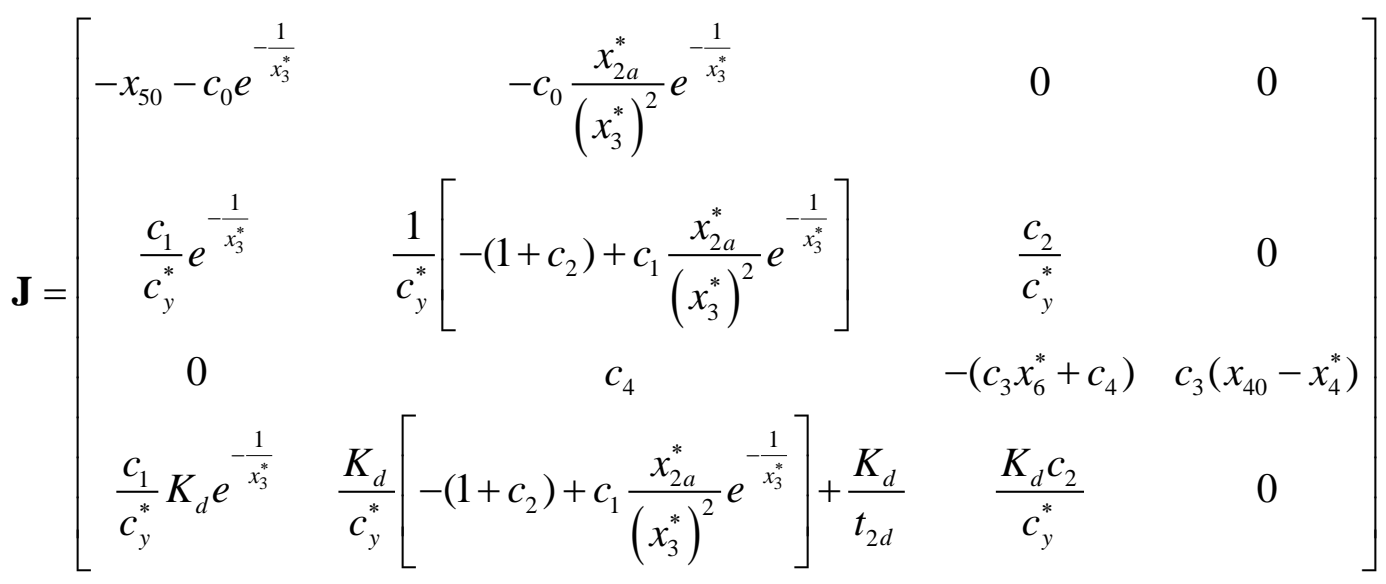

The characteristic equation for the matrix J given in Eq (33) can now be written as:

$$
|\lambda \mathbf{I}-\mathbf{J}|=\lambda^{4}+S_{1} \lambda^{3}+S_{2} \lambda^{2}+S_{3} \lambda+S_{4} ; S_{i}=(-1)^{i} \sum\left|A_{i_{k}}^{i_{k}}\right|
$$

where the terms $S_{i}$ are the sums of the principal minors of $\mathbf{J}$. Taking into account the Routh stability criterion and assuming that $S_{i}>0$ for $i=1,2,3,4$ and that $S_{1} S_{2}-S_{3}>0$, the condition for a self-oscillating behavior is given by: 


$$
S_{1} S_{2} S_{3}-S_{3}^{2}-S_{1}^{2} S_{4}=0
$$

whereas the self-oscillations frequency is obtained as:

$$
\omega=\sqrt{\frac{S_{1} S_{4}}{S_{1} S_{2}-S_{3}}}
$$

The calculations of Eqs (34)-(36) have been carried out through an algorithm similar to the one described in Ref. [12]. Taking $x_{2 a 0}=15$ and $x_{30}=0.032$, Fig 6 shows the variation of $K_{d}$ and the oscillation frequencies given by Eq (36) for various values of $t_{2 d}$ and the corresponding set point $x_{3}^{*}$.

Figure 6

Fig 7 shows the reactor behavior for the values plotted in Fig 6. The set point is $x_{3 e}=0.035$ taking $K_{d}=3.544$ and $\omega=0.914$. These values have been chosen from the low part of the curve $t_{2 d}=0.323(0.1 \mathrm{~h})$ in Fig 6 . The simulation results of Figs $7 \mathrm{a}$ ) and b) show small oscillations for the concentrations and temperatures around the set point, which is due to the integral action. On the other hand, the oscillation frequency obtained from the simulation is very close to that deduced from Fig $6 \mathrm{~b})(\omega=0.914)$, so the analytical calculations are in good agreement with the simulation results. In addition, the conversion of propylene oxide to propylene glycol is acceptable and the mean concentration of the product is almost constant, as shown in Figs 7 c) and 7 d) respectively.

Figure 7

\section{Performance, disturbance rejection and stability}

In this section we shall corroborate that the values of table 1 lead to physically feasible simulation results. In addition, we will analyze the minimum input concentration of reactant A required for the case studied in subsection 3.1 as well as the robustness, disturbance rejection and stability of the limit cycles. Some effects of nonmodeled dynamics will also be discussed. 
The first issue is to analyze the range of admissible temperatures for the input mixtures. Since the propylene oxide is a low-boiling substance, the practical operation cannot exceed a temperature of approximately $353 \mathrm{~K}$ in order to avoid losing oxide by vaporization through the vent system. On the other hand, the melting point of propylene oxide and methanol are $161 \mathrm{~K}$ and $175 \mathrm{~K}$ respectively, so for a mixture with $F_{A 0}=$ $27.18 \mathrm{kmol} / \mathrm{h}, F_{B 0}=462.06 \mathrm{kmol} / \mathrm{h}$ and $F_{B 0}=45.30 \mathrm{kmol} / \mathrm{h}$ the melting point can be estimated as $(27.18 \times 161+462.06 \times 273+45.30 \times 175) /(27.18+462.06+45.30)=259$ $K$. This implies that the dimensionless inlet temperatures must be between 0.0285 and 0.0389, which indicates that it is possible to decrease the melting point by increasing the reactor inlet flow rates (a discussion about this topic can be found in Ref. [22]). With the values indicated in table 1 , the operation range for the dimensionless temperature is $0.0258<x_{30}<0.0389$.

In accordance with Eqs (12), the inlet dimensionless concentrations $x_{2 a 0}, x_{2 b 0}, x_{2}$ and $x_{2 m 0}$ depend on the reference concentrations $C^{\prime}{ }_{A 0}, C^{\prime}{ }_{B 0}, C^{\prime}{ }_{C 0}$ and $C^{\prime}{ }_{M 0}$. These reference values have been obtained by starting the reactor without control for an initial mixture with initial conditions $C_{A}(0)=0 ; C_{B}(0)=55.26 \mathrm{kmol} / \mathrm{m}^{3}, C_{C}(0)=0, C_{M}(0)=$ $0, T(0)=297.22 \mathrm{~K}, T_{j}(0)=297 \mathrm{~K}$ and with the concentrations in the inlet flow rate indicated in table 1 . After three hours, the steady state values in the reactor are $C^{\prime}{ }_{A 0}=$ $0.1547 \mathrm{kmol} / \mathrm{m}^{3}, C^{\prime}{ }_{B 0}=13.8977 \mathrm{kmol} / \mathrm{m}^{3}, C^{\prime}{ }_{C 0}=5.8864 \mathrm{kmol} / \mathrm{m}^{3}$ and $C^{{ }^{\prime}}{ }_{M 0}=5.9352$ $\mathrm{kmol} / \mathrm{m}^{3}$, so it is verified that $10<x_{2 a 0}<50$, which can be considered as an appropriate value range for the reactor.

From the previous considerations, we shall analyze the cases of section 3 . Regarding the case considered in subsection 3.1, several lobe curves are plotted as a function of $K_{d}$ in Fig 8 a). Points $P_{1}$ and $P_{2}$ inside the lobes are obtained for $K_{d 1}=$ 6.7028 and $\mathrm{K}_{\mathrm{d} 3}=338.489$, which correspond to two self-oscillating behaviors. Fig $8 \mathrm{~b}$ ) shows that the inlet concentration $\mathrm{x}_{2 \mathrm{a} 0}$ of reactant $\mathrm{A}$ reaches a minimum value when the set point temperature $\mathrm{x}_{\text {set }}$ is varied assuming different values for the proportional constant of the $\mathrm{PI}_{2}$ controller.

Fig 8 c) shows a sustained oscillation with a conversion of $67 \%$ when $\mathrm{K}_{\mathrm{d} 1}=$ 6.7028, $\mathrm{x}_{2 \mathrm{a} 0}=20$ and $\mathrm{x}_{30}=0.034$ (point $\mathrm{P}_{1}$ of Figs $8 \mathrm{a}$ ) and 8b)). At an arbitrary time $\mathrm{t}$ $=15.44 \mathrm{~h}$, the new values $\mathrm{x}_{2 \mathrm{a} 0}=33, \mathrm{x}_{30}=0.032$, and $\mathrm{K}_{\mathrm{d} 3}=338.4891$ (point $\mathrm{P}_{2}$ with $\mathrm{x}_{\text {set }}$ 
$=0.03625)$ are set, for which the reactor reaches a new sustained oscillation with a mean conversion of $\mathrm{X}_{\mathrm{Am} 2}=76 \%$. In this case the value of $\mathrm{x}_{2 \mathrm{a} 0}$ is not a minimum, which corroborates that the operation costs of the reactor could reach a minimum in self-oscillating mode. Besides, the mean value of the set point temperature is reached for $P_{1}$, whereas the mean set point temperature is 0.0357 for point $P_{2}$. It should be noted that this operation mode uses proportional control without integral action, which would have not been possible in steady state regime.

Figure 8

Fig 9 a) shows the conversion of reactant $A$ as a function of the inlet dimensionless temperature $x_{30}$ assuming different values for $K_{d}$. In accordance with Fig 8 a), the values $x_{2 a 0}=25$ and $x_{30}=0.032$ are inside the lobe for $K_{d 3}=338.4891$, so the reactor reaches a self-oscillating regime for such values. In this case, according to Fig 9

a) the mean conversion is $\mathrm{X}_{\mathrm{A}} \approx 0.65$, whereas the mean conversion for $K_{d 1}=6.7028$ (i.e. without oscillations in steady state) is $\mathrm{X}_{\mathrm{A}} \approx 0.18$. In Fig $9 \mathrm{~b}$ ) we can observe the zone of oscillating behavior corresponding to a defined value of $K_{d}$ and how this plot (together with Fig 9 a)) can be used to choose a desired performance for the reactor. It should be noticed that high values for $x_{30}$ could be inappropriate from an industrial view point because of the volatility of the propylene oxide.

It should be noticed that outside of the oscillation zone -specially for high values of $\mathrm{x}_{30}$ (fig $\left.9 \mathrm{a}\right)$ ) or $\mathrm{x}_{2 \mathrm{a} 0}$ (Fig $\left.9 \mathrm{~b}\right)$ )- the conversion in steady-state is higher than the one in self-oscillating regime, which is due to the high values of equilibrium temperature $\mathrm{X}_{3}$. This issue will be discussed later at the end of this section.

Figure 9

In Fig 10 a) the case considered in subsection 3.2 is resumed. The interpretation is similar to the ones for Figs 9 a) and 9 b), but in this case the conversion is better, which is due to the high values for $\mathrm{x}_{2 \mathrm{a} 0}$. Fig $10 \mathrm{~b}$ ) illustrates an interesting phenomenon that is achieved by using integral action in the $\mathrm{PI}_{2}$ controller (subsection 3.3). With the parameter values indicated in the legend of Fig $10 \mathrm{~b}$ ), the reactor reaches an oscillatory 
behavior with a mean conversion of $44.13 \%$. The equilibrium point $\mathrm{P}_{\mathrm{e}}$ and the corresponding eigenvalues are the following ones:

$$
\begin{gathered}
P_{e}=\left[\begin{array}{ccc}
x_{1 e}=1 & x_{2 e}=25,496 & x_{3 e}=39.841 \\
x_{4 e}=0.384 & x_{5 e}=1 & x_{6 e}=0.0335 \\
x_{7 e}=0.03257 & x_{8 e}=1 & 1.716
\end{array}\right] \\
E g=\left[\begin{array}{ccc}
\lambda_{1}=-1.544+13.722 i & \lambda_{2}=-1.544-13.722 i & \lambda_{3}=-60.493 \\
\lambda_{4}=7.327 .10^{-3}+1.736 i & \lambda_{5}=7.327 .10^{-3}-1.736 i & \lambda_{6}=-1.5007 \\
\lambda_{7}=-1 & \lambda_{8}=-1 & \lambda_{9}=-1
\end{array}\right]
\end{gathered}
$$

It should be noticed that the eigenvalues $\lambda_{1}, \lambda_{2}$ and $\lambda_{7}, \lambda_{8}, \lambda_{9}$ are associated to the $\mathrm{PI}_{1}$ controller and to the inert equations respectively. From the rest of eigenvalues, it can be deduced that $\operatorname{Re}\left[\lambda_{4,5}\right]>0$ and $\left|\lambda_{3}\right| / \operatorname{Re}\left[\lambda_{4,5}\right]>1 ;\left|\lambda_{6}\right| / \operatorname{Re}\left[\lambda_{4,5}\right]>1$, which results in an orbit that is homoclinic to a hyperbolic fixed point, i.e. the so called Shilnikov orbit [11], [27].

At an arbitrary time $\mathrm{t}_{1}=21.61 \mathrm{~h}$, the proportional constant of the $\mathrm{PI}_{2}$ controller is changed to $K_{d}=2681.7$, for which the Shilnikov orbit is destroyed and the set point is reached with a conversion of 0.3624 , i.e. approximately a $16 \%$ lower than in selfoscillating regime. In this case it has been corroborated that the gain/phase margins of the reactor transfer function associated to the feedback loop control $\mathrm{PI}_{2}$ (see Fig 1) are positive and therefore the reactor is stable. Indeed, the equilibrium point is the same but the new eigenvalues are now given by:

$$
E g=\left[\begin{array}{ccc}
\lambda_{1}=-1.544+13.722 i & \lambda_{2}=-1.544-13.722 i & \lambda_{3}=-60.421 \\
\lambda_{4}=-2.128 \cdot 10^{-3}+2.154 i & \lambda_{5}=-2.154 \cdot 10^{-3}-2.154 i & \lambda_{6}=-1.515 \\
\lambda_{7}=-1 & \lambda_{8}=-1 & \lambda_{9}=-1
\end{array}\right]
$$

Operating in steady state, an increase of the cooling jacket temperature of 5.56 ${ }^{\circ} \mathrm{C}$ is assumed at $\mathrm{t}_{2}=27.79 \mathrm{~h}$. In this situation, another Shilnikov orbit appears with a mean conversion that is approximately a $16 \%$ larger than the previous one in steady state.

\section{Figure 10}


Fig 11 a) illustrates another case which illustrates the advantages of the selfoscillating behavior. Taking $\mathrm{x}_{2 \mathrm{a} 0}=25$ and $\mathrm{x}_{30}=0.032$ at $\mathrm{t}=0$, the constants of the $\mathrm{PI}_{2}$ controller are tuned to the values $\mathrm{K}_{\mathrm{d}}=6.7028$ and $\mathrm{t}_{2}=\infty$, with a desired set point $\mathrm{x}_{\text {set }}=$ 0.035. In accordance with Figs 8 a) and 9, the oscillatory behavior is impossible for the considered values. Moreover, the set point cannot be reached by merely changing $\mathrm{K}_{\mathrm{d}}$ since there is no integral action. However, when the $\mathrm{PI}_{2}$ parameters are tuned to $\mathrm{K}_{\mathrm{d}}=$ 338.4891 and $\mathrm{t}_{2}=0.2 \mathrm{~h}$ at $\mathrm{t}=7.71 \mathrm{~h}$, the conversion increases from a steady state value of 0.19 to a mean value of 0.68 in oscillatory regime.

Fig $11 \mathrm{~b}$ ) shows a case of disturbance rejection for which the inlet flow rate is increased from $F_{0}=45.85 \mathrm{~m}^{3} / \mathrm{h}$ to $F_{0 d}=50.96 \mathrm{~m}^{3} / \mathrm{h}$ at $\mathrm{t}=\mathrm{t}_{\mathrm{d}}=30.87 \mathrm{~h}(\tau=100)$. To corroborate the system robustness, it is assumed that the measurement of the reactor temperature is corrupted by random noise once the oscillation regime has been reached at $\mathrm{t}=\mathrm{t}_{\mathrm{d}}=123.5 \mathrm{~h}(\tau=400)$. The noise is modeled as:

$$
\begin{gathered}
x_{50}=x_{50}+f_{a x 50}[X-0.5] \\
x_{3}(t)=x_{3}(t)+f_{a x 3}[X-0.5] \\
x_{6}(t)=x_{6}(t)+\left(K_{t d} / x_{30}\right) f_{a x 3}[X-0.5]
\end{gathered}
$$

where $\mathrm{X}$ is a random variable that is uniformly distributed between 0 and 1 , whereas $\mathrm{f}_{\mathrm{ax} 50}>0$ and $\mathrm{f}_{\mathrm{ax} 3}>0$ are transformation factors to obtain a uniform noise amplitude distribution between $-\mathrm{f}_{\mathrm{ax} 50} / 2$ and $\mathrm{f}_{\mathrm{ax} 50} / 2\left(\mathrm{f}_{\mathrm{ax} 50}=0.1\right.$, which corresponds to $\left.5 \mathrm{~m}^{3} / \mathrm{h}\right)$ and between $-f_{a x 3} / 2$ and $f_{a x 3} / 2\left(f_{a x 3}=10 R / E\right.$, which corresponds to $\left.5.5^{\circ} \mathrm{C}\right)$. The simulation results show that when the random noise is applied, the oscillation regime is destroyed but the mean value of set point temperature is preserved.

Fig $11 \mathrm{c}$ ) shows the variation of the reactant conversion due to the considered disturbances in the inlet flow rate (from $F_{0}=45.85 \mathrm{~m}^{3} / \mathrm{h}$ to $F_{0 d}=39.64 \mathrm{~m}^{3} / \mathrm{h}$ and $F_{0 d}=$ $50.96 \mathrm{~m}^{3} / \mathrm{h}$ respectively). It should be noticed that the mean conversion increases when the inlet flow rate increases.

Another important issue that must be considered is stability. To analyze the stability of periodic solutions we use the monodromy matrix [30] of a particular solution of Eqs (16), which is written in a generalized form as: 


$$
\begin{gathered}
\&(t)=f_{i}\left[x_{i}(t) ; u_{1}(t), u_{2}(t)\right] ; i=1,2 a, 2 b, 2 c, 2 b, 2 m, 3,4,5,6 \\
x_{j}(t)=x_{j}(t+T) \text { for } j=2 a, 2 b, 2 c, 3,4,6
\end{gathered}
$$

Denoting by $\varphi(t: \mathbf{y})$ the trajectories of $\mathrm{Eq}$ (40) as a function of the initial conditions $\mathbf{x}(0) \equiv \mathbf{y}$, the monodromy matrix of $\varphi(t: \mathbf{y})$ for an initial condition $\mathbf{y}=\mathbf{y}^{*}$ is defined as:

$$
M(t)=\frac{\partial \varphi\left(t: \mathbf{y}^{*}\right)}{\partial \mathbf{y}}, t_{0} \leq t \leq t_{0}+T
$$

where $t_{0}$ is an arbitrary initial time. A periodic solution $\mathbf{x}(\mathrm{t})$ will be stable if the modulus of all the eigenvalues of the matrix $M\left(t=t_{0}+T\right)$ are smaller than the unity. Taking into account that the eigenvalues and the eigenvectors of $M\left(t_{0}+T\right)$ are independent of the choice of $\mathrm{t}_{0}$, Fig $11 \mathrm{~d}$ ) shows the eigenvalue moduli of $\mathrm{M}(\mathrm{t})$ for $t_{0} \leq t \leq t_{0}+T$ being $\mathrm{t}_{0}+$ $\mathrm{T}<\mathrm{t}_{\mathrm{d}}$. The moduli of the eigenvalues at $\mathrm{t}=\mathrm{t}_{0}+\mathrm{T}$ are:

$$
M o=\left[\begin{array}{ccc}
9.9834 \cdot 10^{-1} & 9.9700 \cdot 10^{-1} & 1.4162 \cdot 10^{-1} \\
2.4493 \cdot 10^{-5} & 2.4493 \cdot 10^{-5} & 6.9724 \cdot 10^{-16} \\
1.0310 .10^{-3} & 1.0310 .10^{-3} & 1.0310 .10^{-3}
\end{array}\right]
$$

Taking into account that one of the monodromy matrix eigenvalues is always +1 , Eq (42) allows to conclude that the limit cycle is stable. Similar results have been obtained in all oscillation regimes except for Shilnikov orbits, which cannot be considered as purely periodic [11], [27]. To increase the numerical accurateness, the Runge-Kutta-Fehlberg method with a simulation interval of 0.00001 has been used.

Figure 11

It should be remarked that a very simple control structure based on PI control may not be sufficient to control the reactor when parameters such as the reaction rate and the reaction enthalpy are not exactly known. In these cases, a control law based on the compensation of the unknown terms with a high gain term could be used to stabilize the reactor, for which it would be easier to obtain the sustained oscillations once the steady- 
state has been reached. Since the high gain requires large control efforts, it may be convenient substituting it by a control law with uncertainty compensation. Details of these issues can be found in Ref. [28].

Another alternative to the previous problem is to use methods of nonlinear control based on differential geometry. It should be recalled that it is not possible to control the amplitude of the sustained oscillations with PI control only, and in addition the robustness of PI controllers may be limited. Consequently, the geometric robust control with uncertainties could be applied to obtain a self-oscillating mode from a steady-state as indicated in Ref. [29].

It should be noticed that the effect of the delays in the cooling jacket is negligible since the temperature jump between the reactor and the jacket is adequate, as it can be observed in Fig $4 \mathrm{c})$ and Fig 7 b). Regarding the control valves ( $\mathrm{CV}_{1}$ and $\mathrm{CV}_{2}$ of Fig 1$)$, it is necessary chose a valve whose inherent flow characteristics become linear when the valve is installed. In this case, the gain of the control valves $C V_{1}$ and $C_{2}$ can be incorporated to the proportional constant of the controllers $\mathrm{PI}_{1}$ and $\mathrm{PI}_{2}$ respectively.

Finally, we are going to analyze the circumstances in which the conversion in self-oscillating regime is higher to the conversion in steady-state regime, taking into account the cases of self-oscillating behavior studied in subsections 3.1, 3.2 and 3.3. In the case of a $\mathrm{PI}_{2}$ controller without integral action, from Eq (22) it is possible to determine the dimensionless equilibrium point temperature $\mathrm{x}_{3}$, and consequently, the conversion in steady-state regime can be calculated as:

$$
x_{2 a}^{*}=\frac{x_{50} x_{2 a 0}}{x_{50}+c_{0} \exp \left(-1 / x_{3}^{*}\right)} ; X_{A s t}=1-\frac{x_{2 a}^{*}}{x_{2 a o}}
$$

When an integral action is included in the $\mathrm{PI}_{2}$ controller, the set point temperature $\mathrm{x}_{\text {set }}$ is always reached (see Eqs 16), so in this case, the steady-state conversion can be determined by Eqs (43) substituting $x_{3}{ }_{3}$ by $x_{\text {set }}$. From Eqs (30) and (43) the mean conversion $X_{\text {Aos }}$ in self-oscillating regime and the conversion $X_{\text {Ast }}$ in 
steady-state regime can be compared as indicated in Table 3. The numerical results allow to deduce the following conclusions:

1) Proportional control $\left(\mathrm{t}_{2 \mathrm{~d}}=\infty\right)$

- Denoting by $\left(\mathrm{x}_{30}\right)_{\mathrm{L}}$ and $\left(\mathrm{x}_{2 \mathrm{a} 0}\right)_{\mathrm{L}}$ the respective values of $\mathrm{x}_{30}$ and $\mathrm{x}_{2 \mathrm{a} 0}$ inside the lobes, and taking moderate values for $\mathrm{K}_{\mathrm{d}}$, the conversion in self-oscillating regime is higher than the conversion in steady-state regime for $\mathrm{x}_{2 \mathrm{a} 0}<\left(\mathrm{x}_{2 \mathrm{a} 0}\right)_{\mathrm{L}}$ and $\mathrm{x}_{50}=1$.

- For values of $\mathrm{x}_{30}$ and $\mathrm{x}_{2 \mathrm{a} 0}$ outside the lobes and high values of $\mathrm{K}_{\mathrm{d}}$ there are no significant differences between the conversion in steady-state and in selfoscillating, regime. In this case it is possible to reach a steady-state or selfoscillating regime depending on the values for $\mathrm{x}_{30}, \mathrm{x}_{2 \mathrm{a} 0}$ and $\mathrm{K}_{\mathrm{d}}\left(\right.$ with $\mathrm{x}_{50}=1$ ).

2) Proportional plus integral control

- For values of $\mathrm{K}_{\mathrm{d}}$ and $\mathrm{t}_{2 \mathrm{~d}}$ for which the self-oscillating behavior appears (with $\mathrm{x}_{50}$ $=1$ ), the mean conversion is approximately the same that the one corresponding to $\mathrm{x}_{\text {set }}$ in steady-state.

- For values of $\mathrm{K}_{\mathrm{d}}, \mathrm{t}_{2 \mathrm{~d}}, \mathrm{x}_{30}$ and $\mathrm{x}_{2 \mathrm{a} 0}$ for which the self-oscillating behavior is originated by a Shilnikov orbit, the conversion values in self-oscillating regime are higher than the corresponding ones in steady-state for the same $\mathrm{x}_{\text {set }}$ and for $\mathrm{x}_{50} \geq 1$.

\section{Table 3}

\section{Conclusions}

In this paper we have investigated the problem of obtaining induced oscillations to improve the performance of an industrial CSTR for propylene glycol production. It is shown that the sustained oscillations can be deduced by three procedures. The first one is based in the calculation of curves with a cusp point and self-oscillation zones (or lobe curves). When the values for the inlet concentrations and temperatures are inside the lobe the self-oscillation mode is reached. It is corroborated that it is possible to pass from one oscillating mode to another one obtaining a higher mean conversion. 
The $\mathrm{PI}_{2}$ controller parameters that produce self-oscillating behavior without involving the lobe curves have been determined by means of the eigenvalues of the system Jacobian matrix, which must have positive real part to obtain a single unstable equilibrium point. It is demonstrated that the reactor can evolve from a steady-state of low conversion to a self-oscillating regime with a higher mean conversion. The appearance of Shilnikov's orbits has been demonstrated and used to improve the mean conversion of the reactant.

We have obtained graphics to predict the oscillating behavior as a function of the control system parameters, for which there are ranges of values which lead to a high conversion value. Disturbance rejection and stability for the self-oscillating behavior has also been corroborated. The generation of induced oscillations through a control system to produce a higher reaction performance may be very useful from the control engineering viewpoint, especially in the fields of reactor design and in the industrial applications.

\section{References}

[1] Y. Uppal, W. H. Ray, A. B. Poore, On the dynamic behavior of continuous stirred tank reactors, Chem. Eng. Sci. 29 (1974) 967-985.

[2] R. Aris, Elementary Chemical Reactor Analysis. Prentice-Hall Inc. Englewood Cliffs, New Jersey, 1969.

[3] D. A. Vaganov, N. G. Samoilenko, V. G. Abranov, Periodic Regimes of Continuous Stirred tank Reactors, Chem. Eng. Sci. 33 (1978) 1133-1140.

[4] F. Teymour, W. H. Ray, The Dynamic Behavior of Continuous Solution Polymerization Reactors-IV. Dynamic stability and bifurcation analysis of an experimental reactor. Che. Engng. Sci. 44 (1989) 1967- 1982.

[5] J. C. Mankin, J. L. Hudson, Oscillatory and Chaotic Behaviour of a Forced Exothermic Chemical Reaction, Chem. Engng. Sci. 39 (1984) 1807-1814.

[6] I. G. Kevrekidis, L. D. Schmidt, R. Aris, Some common features of periodically forced reacting systems Chem. Engng. Sci. 41 (1986), 227-251.

[7] L. Pellegrini, G. Biardi, Chaotic behaviour of a controlled CSTR, Com. Chem. Engng. 14 (1990) 1237-1247.

[8] M. Dolnik, A. S. Banks, I. R. Epstein, Oscillatory chemical reaction in a CSTR with feedback control of flow rate, J. Phys.Chem. A 101 (1997) 5148-5154.

[9] J. Alvarez-Ramirez, R. Suarez, R. Femat, Robust stabilization of temperature in continuous-stirred tank reactors, Chem. Eng. Sci. 52 (1997) 2223-2230.

[10] J. Alvarez-Ramirez, R. Femat, J. Gonzalez-Trejo, Robust control of a class of uncertain first-order systems with least prior knowledge, Chem. Eng. Sci. 53 (1998) 2701-2710.

[11] R. Femat, Chaos in a class of reacting systems induced by robust asymptotic feedback, Physica D. 136 (2000) 193-204. 
[12] Manuel Pérez, Rafael Font, Marco A. Montava, Regular selfñoscillating and chaotic dynamics of a continuous stirred tank reactor, Comp. \& Chem. Eng. 26 (2002) 889-901.

[13] Manuel Pérez, Pedro Albertos, Self-oscillating and chaotic behaviour of a PIcontrolled CSTR with control valve saturation, J. Pro. Con. 14 (2004) 51-59.

[14] H. S. Fogler, Elements of Chemical Reaction Engineering, Prentice-Hall, New Jersey, 2006

[15] R. Antonelli, A. Astolfi, Continuous stirred tank reactors: easy to stabilize? Automatica, 39 (2003) 1817-1827.

[16] H. S. Sidhu, L. K. Forbes, B. F. Gray, Forced reaction in a CSTR. A comparison between the full system and a reduced model, Chem. Eng. Sci., 52 (1997) 26632676.

[17] V. I. Bykov, S. B. Tsybenova, Parametric Analysis of the Models of a Stirred Tank Reactor and a Tube Reactor, Com. Explo. Shock W. 37 (2001) pp 634-640.

[18] J. M. Douglas, N. Y. Gaitonde, Analytical estimates of the performance of chemical oscillators I \& C Fundamentals, 6, 2 (1967) 265-276.

[19] R. L. Laurence, Ganapathy Vasudevan, Performance of a polymerization reactor in periodic regime, Ind. Eng. Chem. Process Des. Dev., 7 (1968) 427-433.

[20] L. F. Razon, R. A. Schmitz, Multiplicities and instabilities in Chemically reacting systems - a review, Chem Eng. Sci. 42 (1987) 1005-1047.

[21] M. F. Pérez-Polo, M. Pérez-Molina, Saddle-focus bifurcation and chaotic behavior of a continuous stirred tank reactor using PI control, Chem. Eng. Sci., 74 (2012) 79-92.

[22] M. F. Pérez-Polo, M. Pérez-Molina, Self-oscillating chaotic behavior and induced oscillations of a continuous stirred tank reactor with nonlinear control, Chem. Eng. J., 191 (2012) 1512-1527.

[23] K. Otawara, L. T. Fan, Enhancing the performance of spontaneously oscillatory chemical reactions, J. Phys. Chem. A, 101 (1997) 9678-9680.

[24] K. Otawara, L. T. Fan, Increasing the yield from a chemical reactor with spontaneously oscillatory chemical reactions by a nonlinear feedback mechanism, Comp. Chem Eng. 25 (2001) 333-335.

[25] Lucia Russo, Erasmo Mancusi, Pier Luca Maffettone, Silvestro Crescitelli, Symmetry Properties and bifurcation analysis of a class of periodically forced chemical reactors, Che. Eng. Sci., 57 (2002) 5065-5082.

[26] H. Budman, P. L. Silveston, Control of periodically operated reactors, Chem. Eng. Sci. 63 (2008), 4942-4954.

[27] S. Wiggins, Global Bifurcations and Chaos, Springer-Verlag, New York, 1988.

[28] J. Alvarez-Ramirez, R. Suarez, R. Femat, Control of continuous-stirred tank reactors: Stabilization with unknown reaction rates, Chem. Eng. Sci. 51 (1996) 4183-4188.

[29] R. Femat, J. Alvarez-Ramirez, M. Rosales-Torres, Robust asymptotic linearization via uncertainty estimation: regulation of temperature in a fluidized bed reactor, Comp. \& Chem. Eng, 23 (1999) 697-708.

[30] R. Seydel, Practical Bifurcation and Stability Analysis. Springer-Verlag, New York, 1994. 


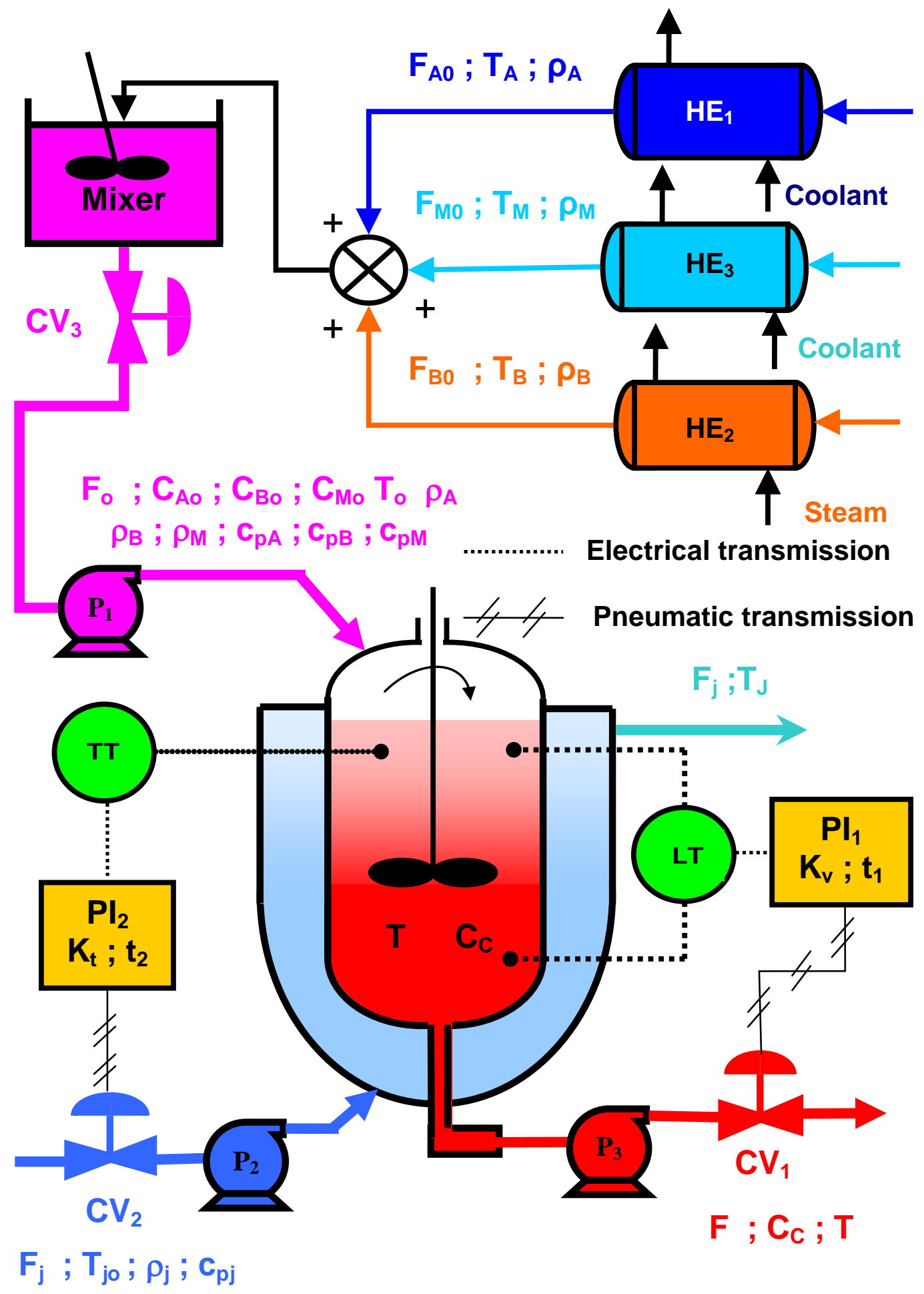

Figure 1 


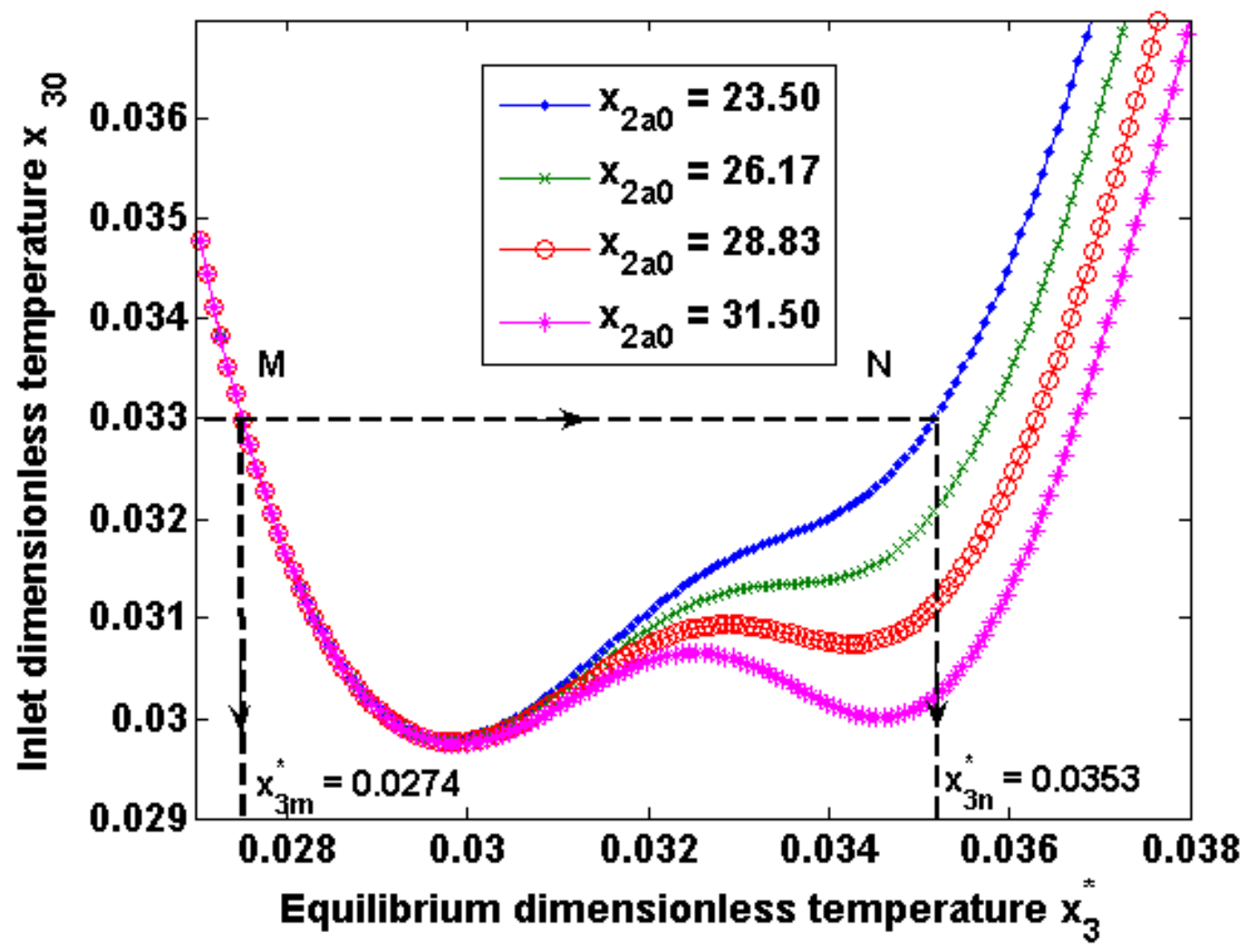

Figure 2 

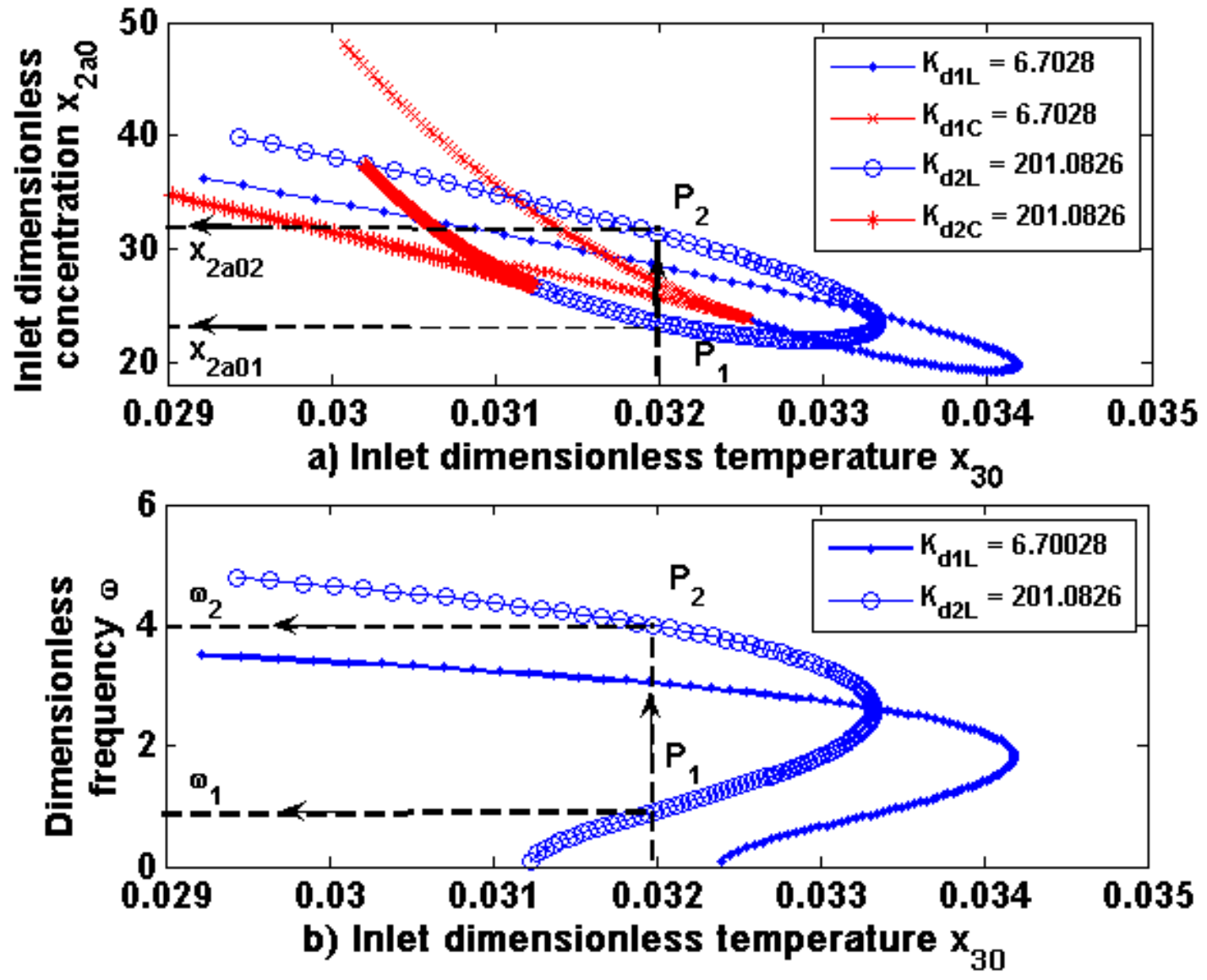

Figure 3 


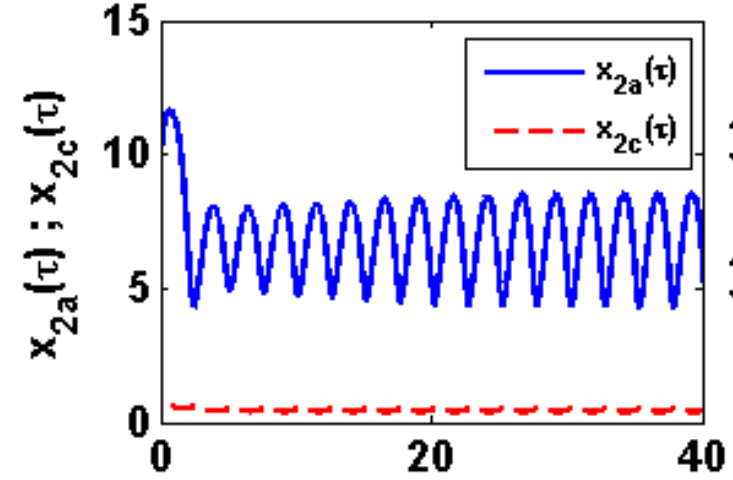

a) Dimensonless time $\tau$

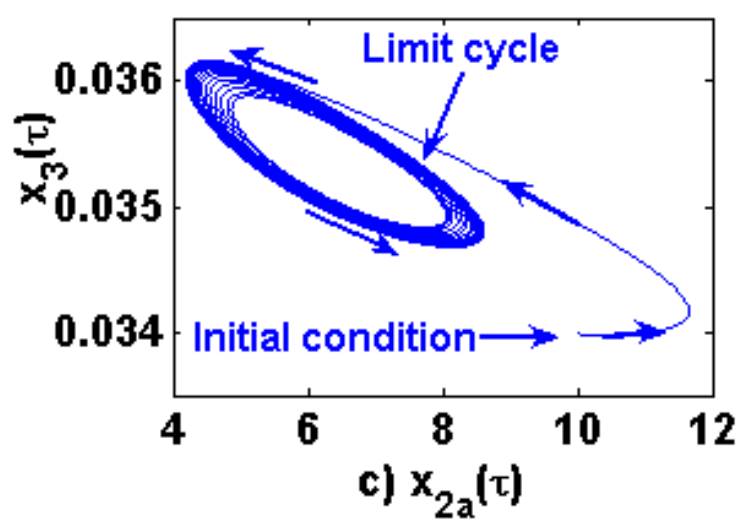

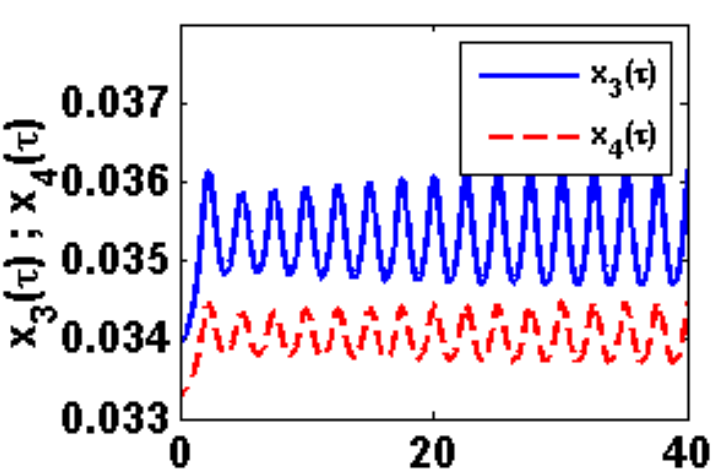

b) Dimensionless time $\tau$

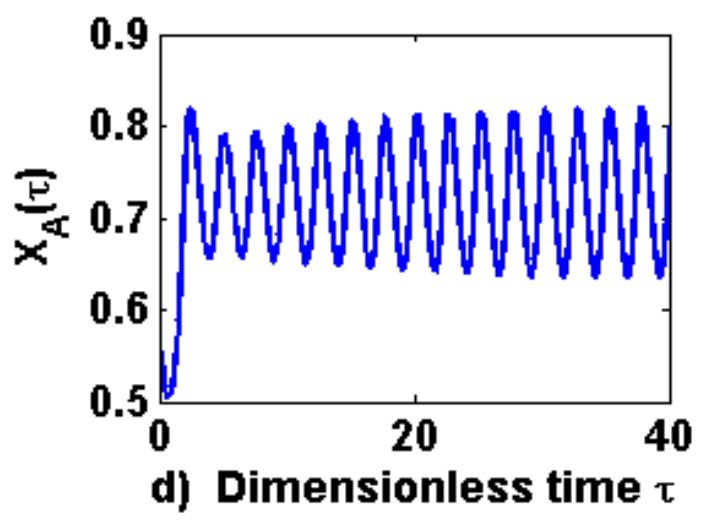

Figure 4 

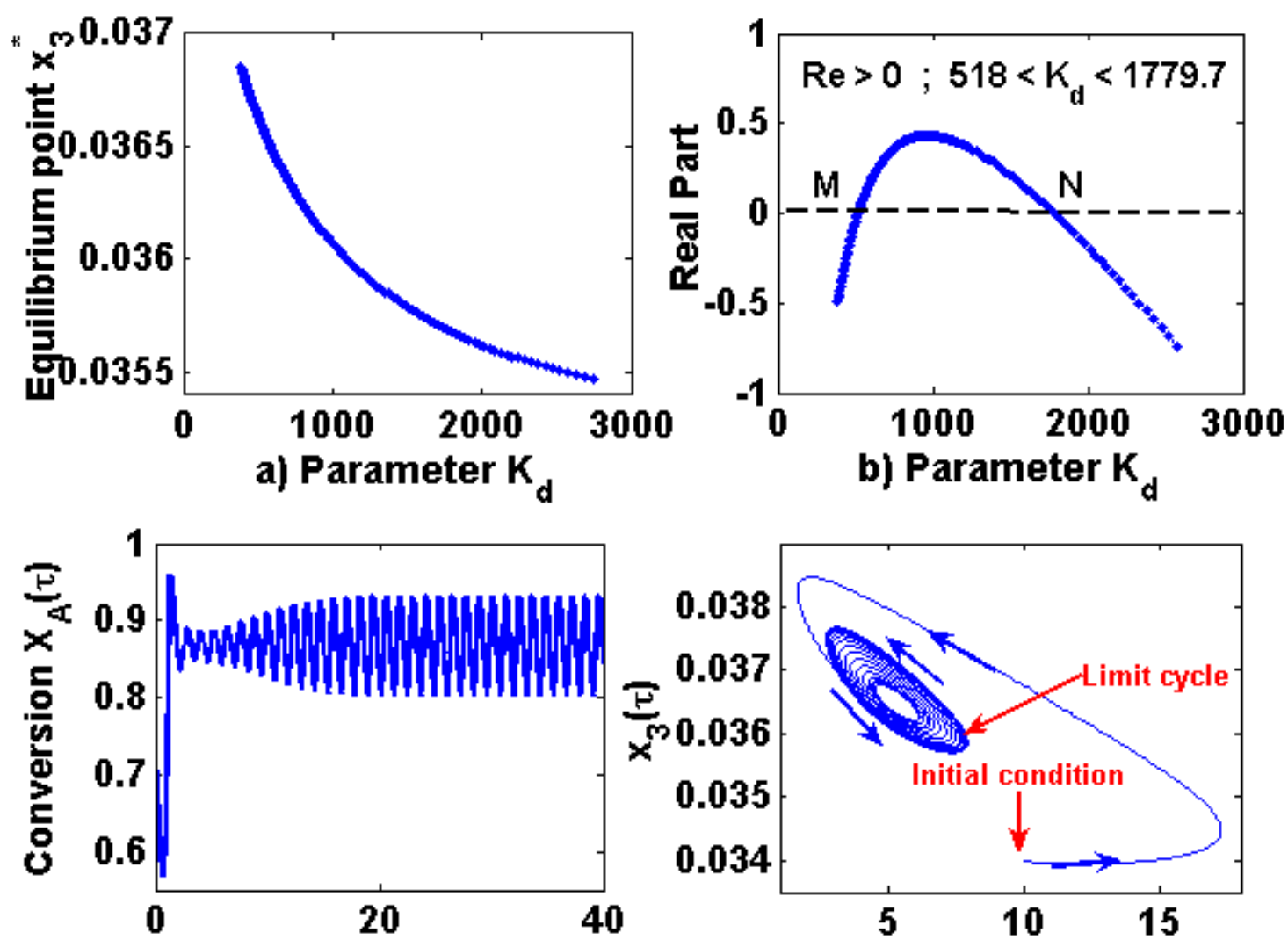

c) Dimensionless time $\tau$

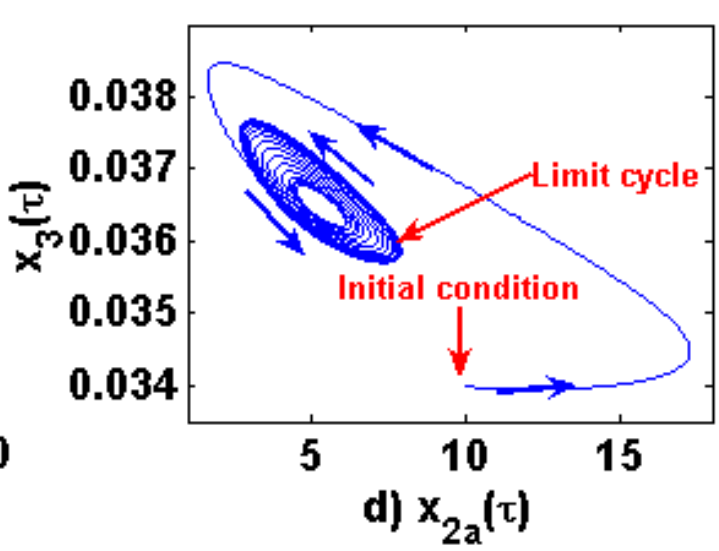

Figure 5 

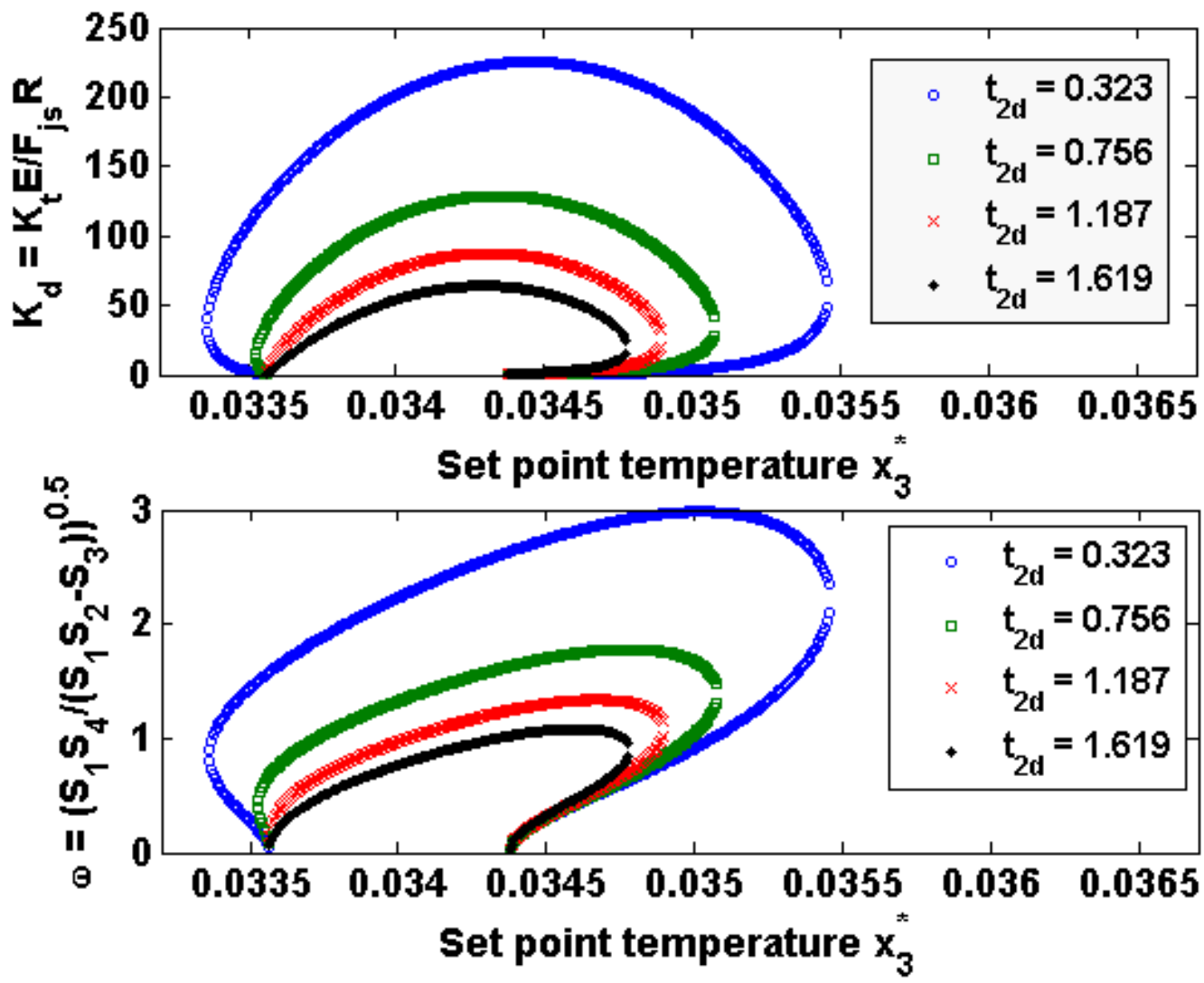

Figure 6 


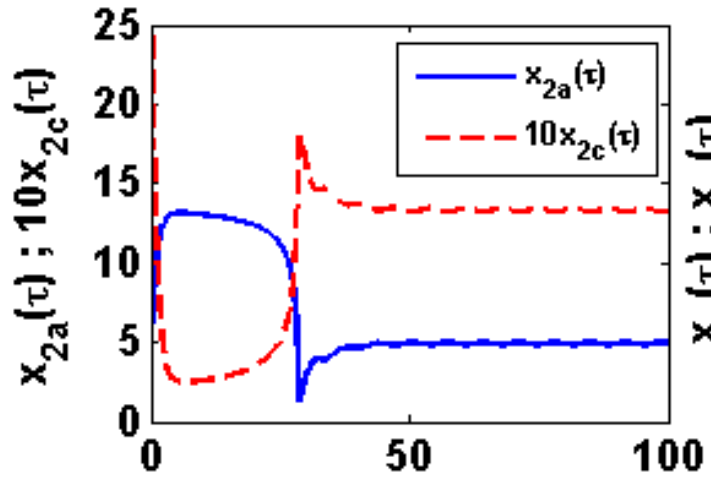

a) Dimensionless time $\tau$

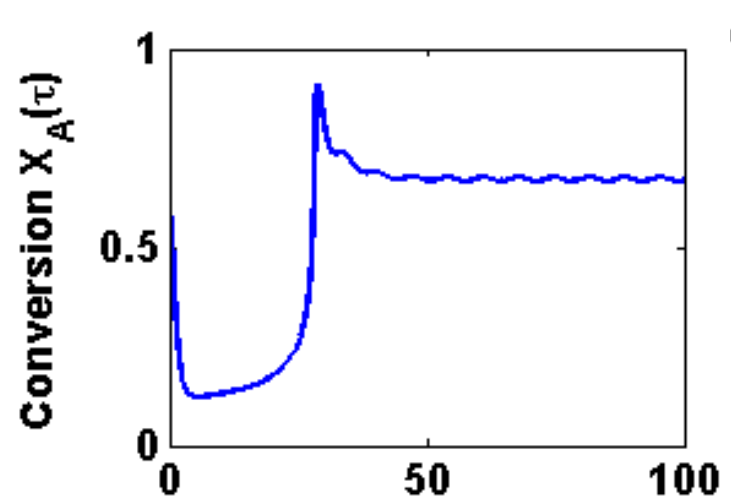

c) Dimensionless time $\tau$

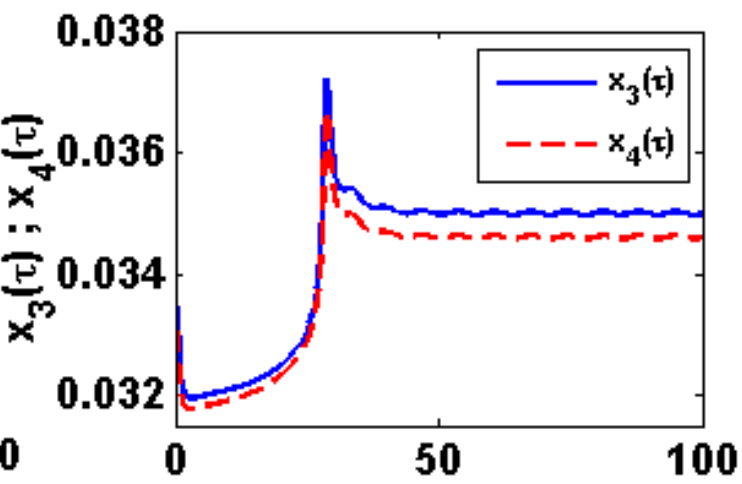

b) Dimensionless time $\tau$

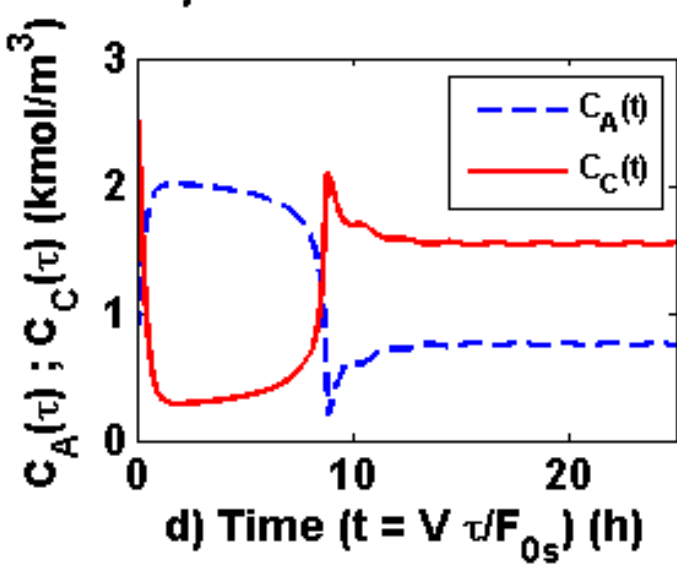

Figure 7 

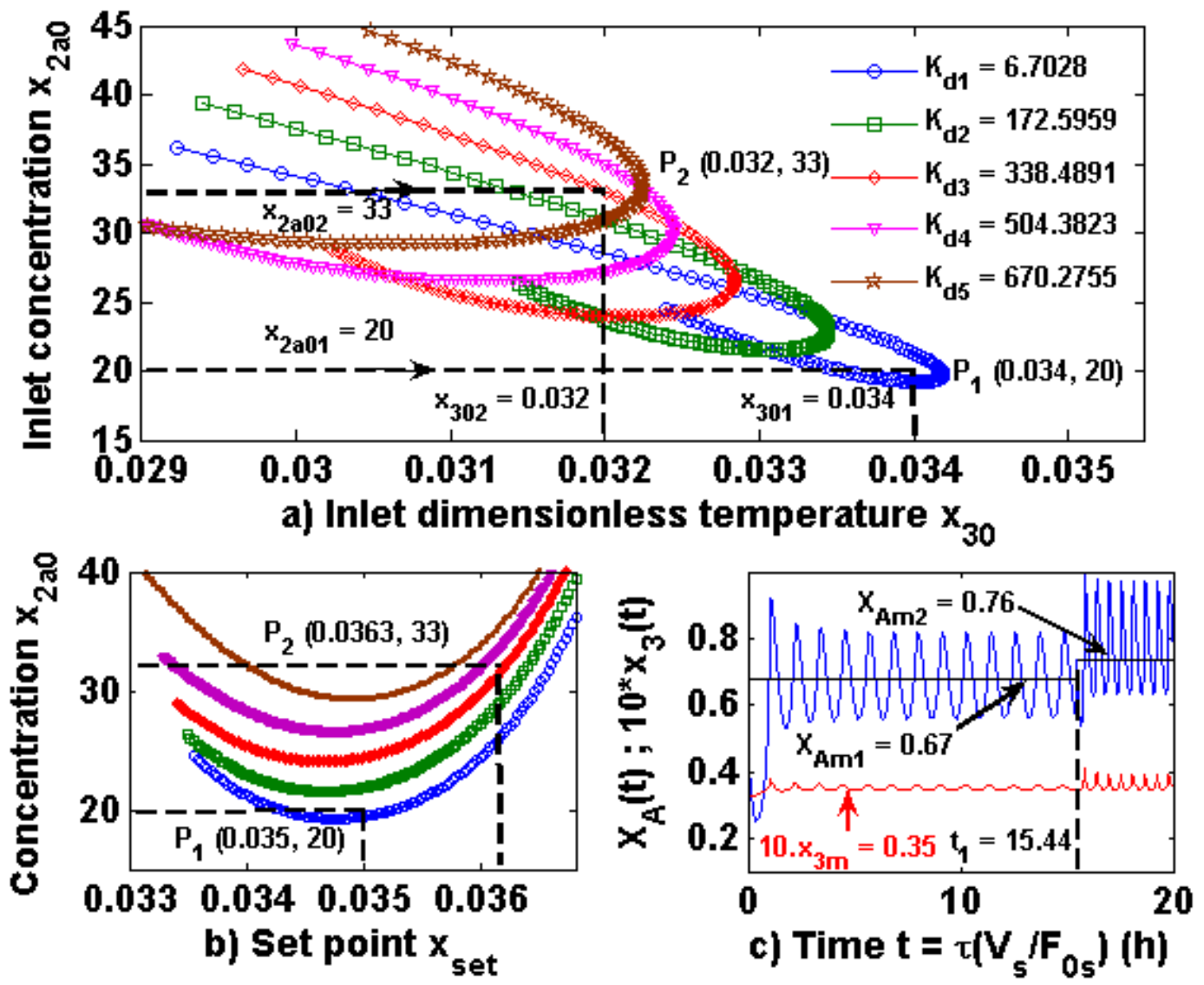

Figure 8 

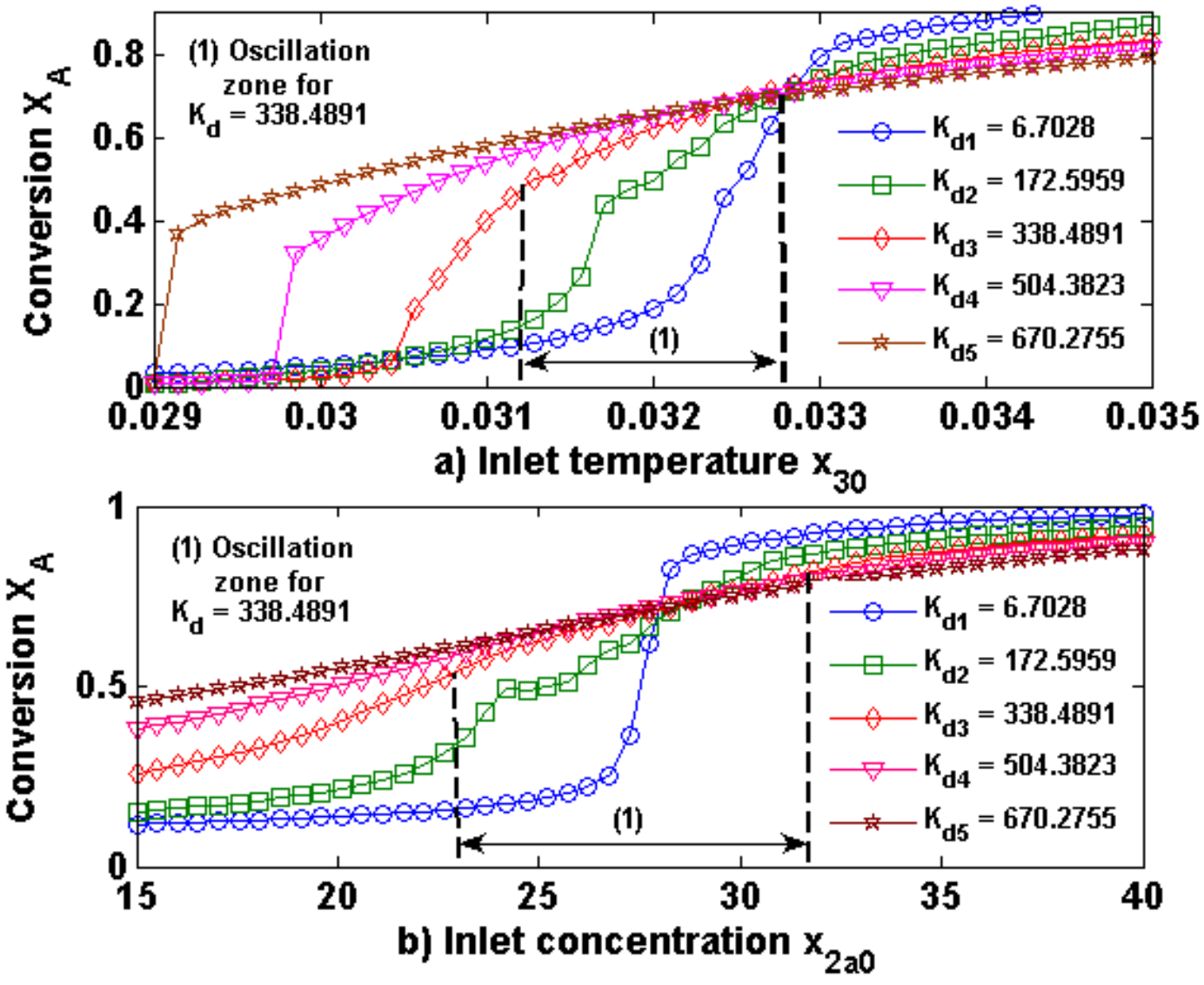

Figure 9 

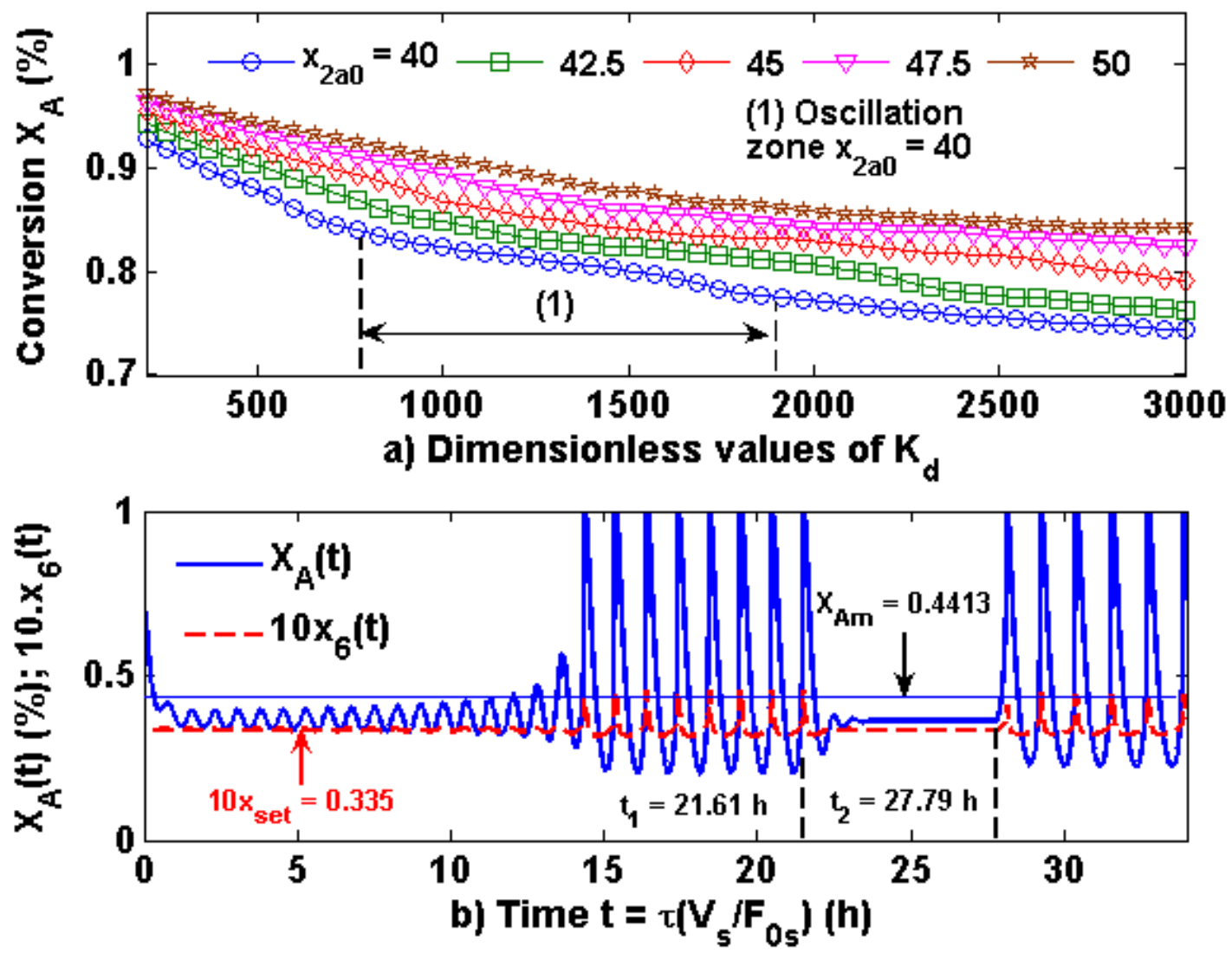

Figure 10 

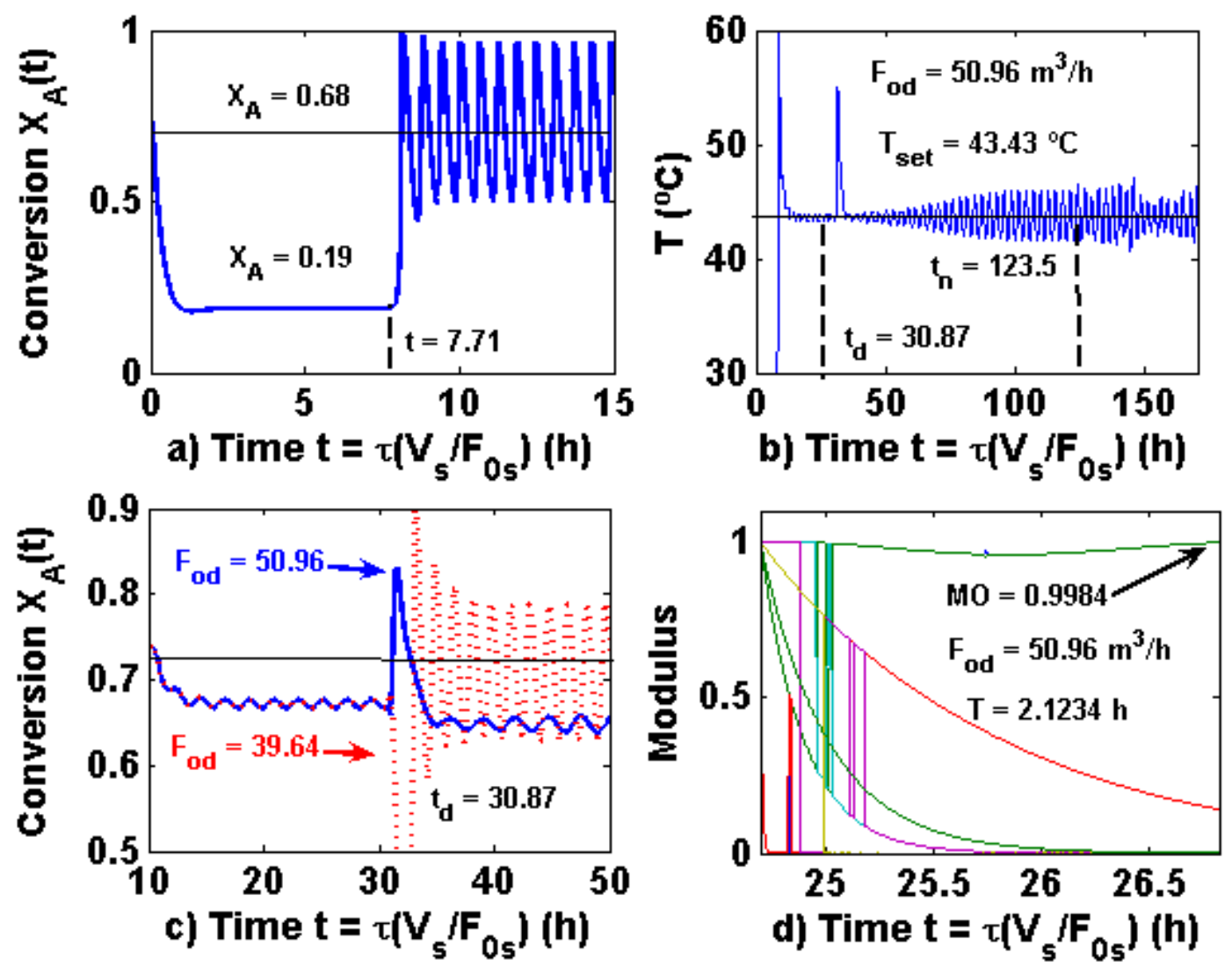

Figure 11 
TABLE 1

PARAMETERS VALUES AND OPERATION CONDITIONS

\begin{tabular}{|c|c|c|}
\hline Variable & Denomination & Value (Dimensionless ) \\
\hline $\mathrm{F}_{\mathrm{A} 0}$ & Molar flow rate of A (kmol A/h) & 272.16 \\
\hline $\mathrm{F}_{\mathrm{B} 0}$ & Molar flow rate of B (kmol B/h) & 907.2 \\
\hline $\mathrm{F}_{\mathrm{M} 0}$ & Molar flow rate of $\mathrm{M}(\mathrm{kmol} \mathrm{A} / \mathrm{s})$ & 273.16 \\
\hline $\mathrm{F}_{0}$ & Inlet volumetric flow rate $\left(\mathrm{m}^{3} / \mathrm{h}\right)$ & 45.85 \\
\hline$\rho_{\mathrm{A} 0}$ & Molar density of A $\left(\mathrm{kmol} / \mathrm{m}^{3}\right)$ & 14.78 \\
\hline$\rho_{\mathrm{B} 0}$ & Molar density of B $\left(\mathrm{kmol} / \mathrm{m}^{3}\right)$ & 55.27 \\
\hline$\rho_{\mathrm{M} 0}$ & Molar density of $\mathrm{M}\left(\mathrm{kmol} / \mathrm{m}^{3}\right)$ & 24.67 \\
\hline V & Reactor volume $\left(\mathrm{m}^{3}\right)$ & 14.16 \\
\hline $\mathrm{V}_{\mathrm{j}}$ & Jacket volume $\left(\mathrm{m}^{3}\right)$ & 1.416 \\
\hline$\alpha$ & Pre-exponential factor. $\left(\mathrm{h}^{-1}\right)$ & $16.96 \times 10^{12}$ \\
\hline $\mathrm{E}$ & Activation energy (kJ/kmol) & 75414 \\
\hline $\mathrm{U}$ & Overall heat transfer $\mathrm{kJ} /\left(\mathrm{h} \cdot \mathrm{m}^{2}{ }^{\circ} \mathrm{C}\right)$ & $2.01 \times 10^{7}$ \\
\hline$A_{j}$ & Transmission area $\left(\mathrm{m}^{2}\right)$ & 33 \\
\hline $\mathrm{C}_{\mathrm{pA}}$ & Heat capacity of A (kJ/kg.K) & 146.52 \\
\hline $\mathrm{C}_{\mathrm{pB}}$ & Heat capacity of B (kJ/kg.K) & 75.35 \\
\hline $\mathrm{C}_{\mathrm{pC}}$ & Heat capacity of C (kJ/kg.K) & 192.57 \\
\hline $\mathrm{C}_{\mathrm{pM}}$ & Heat capacity of M (kJ/kg.K) & 81.63 \\
\hline $\mathrm{C}_{\mathrm{pj}}$ & Heat capacity of $F_{j}(\mathrm{~kJ} / \mathrm{kg} . \mathrm{K})$ & 4.18 \\
\hline $\mathrm{F}_{\mathrm{j}}$ & Volumetric flow of coolant water $\mathrm{F}_{\mathrm{j}}\left(\mathrm{m}^{3} / \mathrm{s}\right)$ & $1.5 \mathrm{~F}_{0}$ \\
\hline$\rho_{j}$ & Density of the coolant water $\left(\mathrm{kg} / \mathrm{m}^{3}\right)$ & 1000 \\
\hline $\mathrm{T}_{0}$ & Inlet stream temperature $\left({ }^{\circ} \mathrm{C}\right)$ & 15.2 \\
\hline $\mathrm{T}_{\mathrm{j} 0}$ & Inlet coolant water temperature $\left({ }^{\circ} \mathrm{C}\right)$ & 15 \\
\hline $\mathrm{R}$ & Perfect-gas constant (kJ/kmol.K) & 8.314 \\
\hline$\Delta \mathrm{H}_{\mathrm{r}}$ & Reaction Enthalpy (kJ/kmol) & -83793 \\
\hline $\mathrm{E}$ & Activation energy $(\mathrm{kJ} / \mathrm{kmol})$ & 75414 \\
\hline $\mathrm{C}^{\prime}{ }_{\mathrm{A} 0}$ & Reference concentration of $\mathrm{A}\left(\mathrm{kmol} / \mathrm{m}^{3}\right)$ & 0.1547 \\
\hline $\mathrm{C}^{\prime}{ }_{\mathrm{B} 0}$ & Reference concentration of $\mathrm{B}\left(\mathrm{kmol} / \mathrm{m}^{3}\right)$ & 13.8977 \\
\hline $\mathrm{C}^{\prime} \mathrm{C} 0$ & Reference concentration of $\mathrm{C}\left(\mathrm{kmol} / \mathrm{m}^{3}\right)$ & 5.8864 \\
\hline $\mathrm{C}_{\mathrm{M} 0}^{\prime}$ & Reference concentration of $\mathrm{M}\left(\mathrm{kmol} / \mathrm{m}^{3}\right)$ & 5.9352 \\
\hline $\mathrm{t}_{1}$ & Reset time of the $\mathrm{PI}_{1}$ controller $(\mathrm{h})$ & 0.005 \\
\hline $\mathrm{K}_{\mathrm{V}}$ & Proportional constant $\mathrm{PI}_{1}$ controller $\left(\mathrm{h}^{-1}\right)$ & 10 \\
\hline $\mathrm{t}_{2}$ & Reset time of the $\mathrm{PI}_{2}$ controller $(\mathrm{h})$ & $0.1-0.5$ \\
\hline $\mathrm{K}_{\mathrm{t}}$ & Proportional constant $\mathrm{PI}_{2}\left(\mathrm{~m}^{3} / \mathrm{h} / \mathrm{K}\right)$ & $0.2-1.6$ \\
\hline
\end{tabular}




\section{TABLE 2}

\section{NOMENCLATURE FOR DIMENSIONLESS VARIABLES}

\begin{tabular}{cccc}
\hline Variable & Denomination & Variable & Denomination \\
$\tau$ & Time & $\mathrm{X}_{4}$ & Jacket temperature \\
$\mathrm{X}_{1}$ & Reactor volume & $\mathrm{X}_{40}$ & Inlet Jacket temperature \\
$\mathrm{x}_{2 \mathrm{a}}$ & Concentration of $\mathrm{A}$ & $\mathrm{X}_{\mathrm{set}}$ & Set point temperature \\
$\mathrm{X}_{2 \mathrm{a} 0}$ & Inlet concentration of $\mathrm{A}$ & $\mathrm{X}_{5}$ & Outlet flow rate \\
$\mathrm{X}_{2 \mathrm{~b}}$ & Concentration of $\mathrm{B}$ & $\mathrm{X}_{50}$ & Initial steady state of $\mathrm{X}_{5}$ \\
$\mathrm{X}_{2 \mathrm{~b} 0}$ & Inlet concentration of $\mathrm{B}$ & $\mathrm{X}_{6}$ & Cooling jacket flow rate \\
$\mathrm{X}_{2 \mathrm{c}}$ & Concentration of C & $\mathrm{K}_{\mathrm{vd}}$ & Proportional constant $\mathrm{PI}_{1}$ \\
$\mathrm{X}_{2 \mathrm{~m}}$ & Concentration of $\mathrm{M}$ & $\mathrm{t}_{1 \mathrm{~d}}$ & Reset time of $\mathrm{PI}_{1}$ \\
$\mathrm{X}_{2 \mathrm{~m} 0}$ & Inlet concentration of $\mathrm{M}$ & $\mathrm{K}_{\mathrm{td}}$ & Proportional constant $\mathrm{PI}_{2}$ \\
$\mathrm{X}_{3}$ & Reactor temperature & $\mathrm{t}_{2 \mathrm{~d}}$ & Reset time of $\mathrm{PI}_{2}$ \\
$\mathrm{X}_{30}$ & Inlet reactor temperature & $\mathrm{C}_{\mathrm{i}} ; \mathrm{C}_{0 \mathrm{i}}$ & Constants in Eqs 15-16 \\
\hline
\end{tabular}




\begin{tabular}{|c|c|c|c|c|c|c|c|}
\hline \multicolumn{8}{|c|}{ TABLE 3} \\
\hline \multicolumn{8}{|c|}{ Self-oscillating behavior $\left(\mathrm{x}_{30}, \mathrm{x}_{2 \mathrm{a} 0}\right)$ inside the lobes } \\
\hline $\mathbf{x}_{\text {set }}$ & $\mathbf{x}_{30}$ & $\mathbf{x}_{2}$ & $2 \mathrm{a0}$ & $\mathbf{K}_{\mathbf{d}}$ & $\mathbf{t}_{2 \mathrm{~d}}$ & $\mathrm{X}_{\text {Aos }}(\%)$ & $\mathrm{X}_{\text {Ast }}(\%)$ \\
\hline 0.035 & 0.0340 & 2 & 0 & 6.7028 & $\infty$ & 0.6700 & - \\
\hline 0.035 & 0.0320 & 3 & 3 & 338.4891 & $\infty$ & 0.7600 & - \\
\hline 0.035 & 0.0330 & 2 & 3 & 172.5959 & $\infty$ & 0.6540 & - \\
\hline 0.035 & 0.0315 & 28 & 8 & 338.4891 & $\infty$ & 0.6320 & - \\
\hline 0.035 & 0.0310 & 3 & 3 & 504.3823 & $\infty$ & 0.7440 & - \\
\hline 0.035 & 0.032 & 3 & 5 & 670.2755 & $\infty$ & 0.8250 & - \\
\hline \multicolumn{8}{|c|}{ Steady-state behavior $\left(x_{30}, x_{2 a 0}\right)$ outside the lobes } \\
\hline $\mathbf{x}_{\text {set }}$ & $\mathbf{x}_{30}$ & $\mathbf{x}_{2}$ & $2 \mathrm{a} 0$ & $\mathbf{K}_{\mathbf{d}}$ & $\mathbf{t}_{2 \mathrm{~d}}$ & $\mathbf{X}_{\text {Aos }}(\%)$ & $\mathbf{X}_{\text {Ast }}(\%)$ \\
\hline 0.035 & 0.0320 & 1( & 0 & 6.7028 & $\infty$ & - & 0.1032 \\
\hline 0.035 & 0.0320 & 1. & 4 & 338.4891 & $\infty$ & - & 0.2399 \\
\hline 0.035 & 0.0320 & 18 & 8 & 172.5959 & $\infty$ & - & 0.1816 \\
\hline 0.035 & 0.0320 & 18 & 8 & 670.2755 & $\infty$ & - & 0.5070 \\
\hline 0.035 & 0.0340 & 18 & 8 & 504.3823 & $\infty$ & - & 0.6322 \\
\hline 0.035 & 0.0360 & 18 & 8 & 670.2755 & $\infty$ & - & 0.7331 \\
\hline \multicolumn{8}{|c|}{ Steady-state or Self-oscillation behavior $\left(\mathrm{x}_{30}, \mathrm{x}_{2 \mathrm{a} 0}\right)$ outside the lobes } \\
\hline $\mathbf{X}_{\text {set }}$ & $\mathbf{x}_{30}$ & $\mathbf{x}_{2}$ & $2 \mathrm{a} 0$ & $\mathbf{K}_{\mathbf{d}}$ & $\mathbf{t}_{2 \mathrm{~d}}$ & $\mathrm{X}_{\mathrm{Aos}}(\%)$ & $\mathbf{X}_{\text {Ast }}(\%)$ \\
\hline 0.035 & 0.0319 & 4( & & 500 & $\infty$ & - & 0.8976 \\
\hline 0.035 & 0.0319 & 4( & & 1000 & $\infty$ & 0.8223 & - \\
\hline 0.035 & 0.0319 & 5 & 0 & 3000 & $\infty$ & - & 0.8566 \\
\hline \multicolumn{8}{|c|}{ Self-oscillating behavior with $\mathrm{PI}_{2}$ control } \\
\hline $\mathbf{X}_{\text {set }}$ & $\mathbf{x}_{30}$ & $\mathbf{x}_{2 \mathrm{a} 0}$ & $\mathbf{x}_{50}$ & $\mathbf{K}_{\mathbf{d}}$ & $\mathbf{t}_{2 \mathrm{~d}}$ & $\mathrm{X}_{\mathrm{Aos}}(\%)$ & $\mathrm{X}_{\text {Ast }}(\%)$ \\
\hline 0.0330 & 0.0320 & 40 & 1 & 1018.639 & 0.3238 & 0.2812 & 0.2670 \\
\hline 0.0350 & 0.0319 & 25 & 1 & 781.6775 & 0.3238 & 0.6792 & 0.6680 \\
\hline 0.0350 & 0.0319 & 35 & 1 & 2165.364 & 0.3239 & 0.6679 & 0.6680 \\
\hline 0.0350 & 0.0319 & 35 & 1 & 1894.574 & 0.6477 & 0.6779 & 0.6680 \\
\hline 0.0360 & 0.0319 & 25 & 1 & 220.969 & 0.6477 & 0.8186 & 0.8168 \\
\hline \multicolumn{8}{|c|}{ Self-oscillating behavior with $\mathbf{P I}_{2}$ control (Shilnikov orbits) } \\
\hline $\mathbf{x}_{\text {set }}$ & $\mathbf{X}_{30}$ & $\mathbf{x}_{2 \mathbf{2} 0}$ & $\mathbf{X}_{50}$ & $\mathbf{K}_{\mathbf{d}}$ & $\mathbf{t}_{2 \mathrm{~d}}$ & $\mathrm{X}_{\mathrm{Aos}}(\%)$ & $\mathrm{X}_{\text {Ast }}(\%)$ \\
\hline 0.0330 & 0.0310 & 30 & 1 & 489.566 & 0.6477 & 0.3480 & 0.2670 \\
\hline 0.0335 & 0.0310 & 40 & 1 & 1725.460 & 0.6477 & 0.4413 & 0.3650 \\
\hline 0.0335 & 0.0319 & 25 & 1 & 519.431 & 0.3238 & 0.4673 & 0.3650 \\
\hline 0.0350 & 0.0319 & 20 & 4 & 449.077 & 3.2387 & 0.4341 & 0.3364 \\
\hline 0.0360 & 0.0319 & 25 & 2 & 853.602 & 3.2387 & 0.6750 & 0.5329 \\
\hline
\end{tabular}




\section{Legend of figures}

Figure 1. Layout of a continuous stirred tank reactor (CSTR) for propylene glycol production. Control valves, pumps and heat exchangers are respectively denoted by $\mathrm{CV}_{\mathrm{i}}, \mathrm{P}_{\mathrm{i}}$ and $\mathrm{HE}_{\mathrm{i}}(\mathrm{i}=1,2,3)$. TT is the temperature transmitter and $\mathrm{LT}$ is the level transmitter. $\mathrm{PI}_{1}$ and $\mathrm{PI}_{2}$ are the PI controllers for the outlet flow rate and the coolant flow rate respectively.

Figure 2. Inlet dimensionless temperatures vs the equilibrium dimensionless temperature for various values of the inlet dimensionless concentration $x_{2 a 0}\left(K_{d 1}=\right.$ 6.7028). Parameter values are indicated in the legend of Fig 3.

Figure 3. a) Lobe curves and curves with a cusp point for various values of the $\mathrm{PI}_{2}$ controller proportional constant $\left(K_{d}\right)$. The parameter values are $x_{30}=0.032\left(T_{0}=15.32\right.$ $\left.{ }^{\circ} \mathrm{C}\right), x_{40}=0.0313\left(T_{j 0}=15{ }^{\circ} \mathrm{C}\right), F_{j s}=68.775 \mathrm{~m}^{3} / \mathrm{h}, K_{v}=10 \mathrm{~h}^{-1}\left(K_{v d}=3.0876\right), t_{1}=$ $0.005 h\left(t_{1 d}=0.0162\right), x_{50}=1, T_{s e t}=43.66{ }^{\circ} \mathrm{C}\left(x_{3 e}=0.035\right), K_{t 1}=0.050968 \mathrm{~m}^{3} / \mathrm{h} . \mathrm{K}$ $\left(K_{t d 1}=0.21369, K_{d 1}=K_{t d 1} / x_{30}=6.7028\right), K_{t 2}=1.52906 \mathrm{~m}^{3} / \mathrm{h} \cdot K\left(K_{t d 2}=6.41084\right), K_{d 2}$ $=K_{t d 2} / x_{30}=201.08, t_{2 d}=\infty$. b) Dimensionless frequency corresponding to lobe curves is plotted in Fig 3 a)

Figure 4. Simulation results of Eqs (16). a) Dimensionless concentration of the propylene oxide $x_{2 a}(\tau)$ and propylene glycol $x_{2 c}(\tau)$ vs time. b) Dimensionless temperatures of the reactor $\left(x_{3}\right)$ and the jacket $\left(x_{4}\right)$. The coordinates of point $\mathrm{P}_{1}$ shown in Fig 3 a) are: $P_{1}\left(x_{2 a 0}=23.5, x_{30}=0.032\right), x_{50}=1, K_{v}=10 h^{-1}\left(K_{v d}=3.0876\right), t_{1}=$ $0.005 h\left(t_{1 d}=0.0162\right), K_{t}=1.52906 \mathrm{~m}^{3} / \mathrm{h} . K\left(K_{t d}=6.41084 ; K_{d}=K_{t d 2} / x_{30}=201.08\right)$, $t_{2 d}=\infty$. The simulation step is $T=0.002$ and the initial conditions are $x_{0}=[1,10,5,1$, $5,0.034,0.0323,1.2,0.7971]$. c) Limit cycle in the phase plane $\mathrm{x}_{2 a}(\tau)-x_{3}(\tau)$. d) Oscillating conversion $X_{A}(\tau)$ of the propylene oxide vs dimensionless time, for which the mean value is approximately 0.73. A Fourth-order Runge-Kutta integration scheme has been used.

Figure 5. a) Variation of the dimensionless equilibrium point temperature against the dimensionless control parameter $K_{d}$. b) Zone of the unstable equilibrium points for which one of the eigenvalues corresponding to the equilibrium temperatures shown in Fig 5 a) have positive real part $\left(x_{2 a 0}=40, T_{\text {set }}=43.66{ }^{\circ} \mathrm{C}\right)$. b) Oscillating conversion $X_{A}(\tau)$ of propylene oxide, whose mean value is approximately 0.88. c) Limit cycle in the phase plane $\mathrm{x}_{2 a}(\tau)-x_{3}(\tau)$. The parameter values are $x_{2 a 0}=40, x_{30}=0.0319, x_{50}=1, T_{\text {set }}$ $=43.66{ }^{\circ} \mathrm{C}, K_{v}=10 \mathrm{~h}^{-1}\left(K_{v d}=3.0876\right), t_{1}=0.005 \mathrm{~h}\left(t_{1 d}=0.0162\right), K_{d}=600$ and $t_{2 d}=$ $\infty$, The simulation step is $T=0.002$ and the initial conditions are $x_{0}=[1,10,5,1,5$, $0.034,0.0323,1.2,0.3944]$.

Figure 6. a) Combinations of the $\mathrm{PI}_{2}$ controller parameters $K_{d}$ and $t_{2 d}$ vs the set point temperature to produce a reactor self-oscillating behavior. b) Oscillation frequencies corresponding to the parameter values indicated in Fig 6 a). 
Figure 7. Simulations results including the $\mathrm{PI}_{2}$ controller parameter $t_{2 d}$. a) Concentrations of the propylene oxide $x_{2 a}(\tau)$ and propylene glycol $x_{2 c}(\tau)$ vs time. b) Dimensionless temperatures of the reactor $x_{3}(\tau)$ and the jacket $x_{4}(\tau)$. The parameter values are $x_{2 a 0}=15, x_{30}=0.0319, x_{50}=1, T_{\text {set }}=43.66^{\circ} \mathrm{C}, K_{v}=10 h^{-1}\left(K_{v d}=3.0876\right)$, $t_{1}=0.005 h\left(t_{1 d}=0.0162\right), K_{d}=3.5443, \omega=0.9136$ and $t_{2 d}=0.3229$. The simulation step is $T=0.002$ and the initial conditions are $x_{0}=[1,5,2.5,0.5,2.5,0.0342,0.0323$, $1.2,0.9964]$. c) Conversion $X_{A}(\tau)$ of the propylene oxide, whose mean value is approximately 0.7. d) Concentrations of the propylene oxide $x_{2 a}(\tau)$ and propylene glycol $x_{2 c}(\tau)$ vs time. Parameter values are indicated in the legend of Fig 10.

Figure 8. a) The self-oscillation zones inside the lobe curves are plotted for various values of $K_{d}$ (dimensionless proportional action of the $\mathrm{PI}_{2}$ controller) as a function of $x_{2 a 0}$ and $x_{30}$. b) Inlet dimensionless concentration of reactant $\mathrm{A}$ as a function of the set point temperature for the values of $K_{d}$ indicated in Fig 8 a). c) Conversion and reactor temperature in self-oscillating regime for $\mathrm{x}_{2 \mathrm{a} 0}=20, \mathrm{x}_{30}=0.034, \mathrm{x}_{\mathrm{set}}=0.035$ and $\mathrm{K}_{\mathrm{d} 1}=$ 6.7028. At $\mathrm{t}=15.4 \mathrm{~h}$ the previous parameters are changed to $\mathrm{x}_{2 \mathrm{a} 0}=33, \mathrm{x}_{30}=0.032, \mathrm{x}_{\text {set }}$ $=0.03625$ and $\mathrm{K}_{\mathrm{d} 1}=338.4891$. A fourth-order Runge-Kutta integration scheme has been used with a simulation step of 0.002 and initial conditions $x_{0}=[1,10,5,1,0.5$, $0.032,0.0304,1.2,0.9424]$.

Figure 9. a) Mean value of the propylene oxide conversion for the case of subsection 3.1, which is plotted as a function of the inlet dimensionless temperature assuming a constant value for $x_{2 a 0}$. The parameter values are $x_{2 a 0}=25, x_{50}=1, T_{\text {set }}=43.66{ }^{\circ} \mathrm{C}, t_{2 d}$ $=\infty, K_{v}=10 h^{-1}\left(K_{v d}=3.0876\right)$ and $t_{1}=0.005 h\left(t_{1 d}=0.0162\right)$. b) Mean value of the propylene oxide conversion for the case of subsection 3.1, which is plotted as a function of the inlet dimensionless concentrations assuming a constant value for $x_{30}$. The parameter values are $x_{30}=0.0319, x_{50}=1, T_{\text {set }}=43.66^{\circ} \mathrm{C}, t_{2 d}=\infty, K_{v}=10 h^{-1}\left(K_{v d}=\right.$ 3.0876) and $t_{1}=0.005 h\left(t_{1 d}=0.0162\right)$. The simulation time is $t_{m}=50$ and the simulation step is 0.005 .

Figure 10. a) Steady state conversion of propylene oxide for the case of subsection 3.2, which is plotted as function of $K_{d}$ assuming a constant value for $x_{30}$. The parameter values are $x_{30}=0.0319, x_{50}=1, T_{\text {set }}=43.66^{\circ} \mathrm{C}, t_{2 d}=\infty, K_{v}=10 h^{-1}\left(K_{v d}=3.0876\right)$ and $t_{1}=0.005 h\left(t_{1 d}=0.0162\right)$. The simulation time is $t_{m}=50$ and the simulation step is 0.005 . b) Mean conversion of propylene oxide taking $x_{2 a 0}=40, x_{30}=0.031, x_{\text {set }}=$ $0.0335, t_{2 d}=0.6477$ and $K_{d}=1725$. Constant $K_{t}$ is changed to 400 at $t=t_{1}=21.61 \mathrm{~h}$, and a disturbance of $5.56{ }^{\circ} \mathrm{C}$ is applied in the inlet cooling flow rate at $t=t_{2}=22.79 \mathrm{~h}$.

Figure 11. a) Conversion of propylene oxide taking $x_{2 a 0}=25, x_{30}=0.032, x_{\text {set }}=0.032$, $K_{d}=6.7028, t_{2}=\infty$ for $t \leq 7.71, K_{d}=338.4891$ and $t_{2}=0.2 \mathrm{~h}$ for $\left.\mathrm{t}>7.71 \mathrm{~h} . \mathrm{b}\right)$ Transitory state and self-oscillating behavior with an input flow rate disturbance of $F_{0 d}$ $=50.96 \mathrm{~m}^{3} / \mathrm{h}$ at $t=t_{d}=30.87 \mathrm{~h}$. Random noise is applied at $t=t_{n}=123.5 \mathrm{~h}$. c) Variation of the mean conversion of reactant with disturbances $F_{0 d}=39.64 \mathrm{~m}^{3} / \mathrm{h}$ and $F_{0 d}=50.96 \mathrm{~m}^{3} / \mathrm{h}$. d) Modulus of the eigenvalues of the monodromy matrix in an arbitrary period. 